\title{
DYNAMICS OF MULTIDIMENSIONAL POVERTY AND \\ UNI-DIMENSIONAL INCOME POVERTY: AN EVIDENCE \\ OF STABILITY ANALYSIS FROM CHINA
}

\author{
Sabina Alkire* and Yingfeng Fang** \\ [This is an Author's Accepted Manuscript; the paper was published in Social Indicators \\ Research online, April 2018. Link.]
}

\begin{abstract}
In this paper, we construct an illustrative multidimensional poverty index for China and compare it with income poverty using the panel data from multiple waves of the China Health and Nutrition Survey. We use first order stochastic dominance method and regression analysis to test the stability of multidimensional poverty measures and probe the often-observed mis-match between multidimensional measures and income measures. We find as expected that China's multidimensional poverty is significantly higher in rural areas and in the less developed western provinces. But relative to the income poverty, the multidimensional poverty is less volatile. Also, the ranking of provinces by income and multidimensional poverty varies. The multidimensional poverty measures are somewhat sensitive to the large change of weight, but if we control the indicators' weight, then the multidimensional poverty measures are stable to a change of indicators.
\end{abstract}

Keywords: poverty measurement; multidimensional poverty; stability; weight; robustness tests, mis-match

JEL Classification: I3 I32 O1 D63

\footnotetext{
* Oxford Poverty and Human Development Initiative, University of Oxford, United Kingdom.

** Economics and Management School, Wuhan University, China. eco_yingfeng@whu.edu.cn.
} 


\section{Introduction}

During the last thirty years, China's income poor population has declined sharply. Further, the millennium development goals for China were reached or nearly reached. In year 2011, China's government adjusted the rural poverty line upwards to RMB 2300 (in 2010 prices) per year which is about $\$ 1.797$ per day converted by PPP 3.506 in 2011 according to the international Comparison Program (ICP) from the World Bank $^{1}$. According to this poverty line, the official number of poor people in China's rural areas is 166 million and rural poverty incidence was $17.2 \%$ in year 2010 . In 2015, China still has 55.75 million poor population in rural areas, and the poverty incidence is $5.7 \%$. So there have been strong gains even in recent times. Yet income poverty reduction remains a fundamental challenge. But before going to policy making, we must re-consider how to measure poverty, that is, which means should be chosen to target the poor.

At present, there are two kinds of measurement methods: traditional income poverty measures and new multidimensional poverty measures. Because each of these two measures address different definitions of poverty, and both seem important, it is not a question of choosing which one is better for poverty reduction. Rather, both measures are often used together as official poverty statistics, each of which captures something important, and provides policy-relevant guidance. ${ }^{2}$ However although it is recognized that the measures differ, the respective strengths and reasons for their differences and complementarities are not yet sufficiently understood. In this paper, we use panel data to study the dynamics of both multidimensional and income poverty in China, to analyze their differences, and to assess the robustness or stability of the multidimensional measures to changes in weights and indicators.

Poverty has traditionally been considered in income space, and people have been identified as

\footnotetext{
${ }^{1}$ The PPP data is available here: $\underline{\text { link. }}$.

${ }^{2}$ For examples of governments having both official poverty statistics see, for example, Ecuador, Colombia, El Salvador, Costa Rica, Chile, and Bhutan. See Alkire et al (2015) chapter 1.
} 
poor if they do not have enough money to meet their food requirements or their basic needs. Furthermore, the headcount ratio is the most widely used indicator in policy making. However, the headcount ratio is completely insensitive to the distribution of income among the poor. Sen (1976) argues that a poverty index should reflect the depth of poverty and inequality among the poor and hence must satisfy the monotonicity axiom and transfers. The Sen index fulfils these requirements. But because Sen's poverty index couldn't communicate information as transparently as headcount ratio does, Sen's index less common in empirical application. Foster et al. (1984) observes that Sen's "ranking weighting" does not respect the axiom of subgroup consistency hence subgroup decomposability. With an alternative "shortfall weighting", Foster, et al. obtain a class of decomposable poverty indexes (FGT poverty indexes) which possess a series of good properties. Yet while the FGT poverty indexes are widely used to measure poverty, the headcount ratio remains the prominent measure because it can be easily understood and communicated.

Because of its familiarity, income data appear to be easy to operate policy makers engaged in in monitoring poverty, and in targeting the poor. But markets are imperfect; there are many non-monetary attributes which can't be traded in the market. In addition, in policy terms, income is a result, which can't explain why these people are in poverty. The insufficient information or signals may also make policies such as cash transfers inefficient, because they do not touch the root causes. Sen argues that we couldn't just focus on income factors in poverty reduction, we should also consider how investments in health and education and so on are both of intrinsic value and also instrumental to economic productivity. Sen puts forward the capability approach and attributes the poverty to lack of capability in different dimensions. Hence, Anand and Sen (1997), Bourguignon and Chakravarty (2003), Atkinson (2003), and Alkire and Foster (2007), all argue that poverty is multidimensional and should be measured in the multidimensional perspective. The Human Poverty Index (HPI) was first proposed by Anand and Sen; later measurement methodologies make use of recently available micro data to propose counting approaches to measuring poverty. 
Ravallion (2011) argued that it should aim for a credible set of multiple indicators. However the 2016 Report of the Commission on Global Poverty chaired by Tony Atkinson argues that the World Bank should measure non-monetary dimensions of poverty and include in a measure of overlapping deprivations - in other words, a multidimensional poverty index (World Bank 2016). Thus, it is becoming widely accepted that it is essential to measure the poverty from multidimensional, as well as monetary, perspective.

For multidimensional poverty measurement, it is necessary to choose the dimensions and identify who is poor in the first step. Based on the capability approach, Sen $(1985,1999)$ states, the capability of a person reflects the alternative combinations of functionings the person can achieve, and from which he/she can choose one collection. The capability approach is based on a view of living as a combination of various "doings and beings". Constrained by the data available, we only chose some elementary and important functionings for this paper, such as the ability to be well nourished, well-educated and well sheltered, the capability of escaping avoidable morbidity and premature mortality, and so on. According to the capability approach, following the global Multidimensional Poverty Index (MPI) explicated in Alkire and Santos $(2010,2014)$ and published by UNDP's Human Development Reports, this paper chooses three equally-weighted dimensions: Education, health and living of standard.

The next steps are to identify who is poor and aggregate deprivations of the poor people into an overall measure of poverty. Which approach shall we use? Tsui (2002) generalizes the basic axioms of income poverty measurement into multidimensional poverty measurement, and describes an axiomatic and generalized multidimensional poverty index. Bourguignon and Chakravarty (2003) also built a class of multidimensional poverty measures that extend the FGT class to many dimensions and satisfy a set of important properties. But their measures require cardinal data and assuming the same elasticity of substitution between different dimensions, and these features restrict their use in practice. Deutsch and Silber (2005) made a systematic 
comparison of four approaches to multidimensional poverty analysis based respectively on the theory of fuzzy sets, information theory, efficiency analysis and axiomatic poverty indices. Thus different methodological options exist - particularly if data are cardinal.

Although there is widespread agreement that it should measure poverty from multidimensional perspective, few empirical measures had been used in policy. This may have reflected the more complicated aggregation procedures and difficult data requirements, and choices of parameters required for other measures. This paper implements the Alkire and Foster $(2007,2011)$ "dual-cutoff approach" to calculate the adjusted headcount ratio multidimensional poverty index (MPI). This measure also extends the FGT poverty index and has many good properties. Policy-oriented applications have been implemented by many governments, and by international agencies including the United Nations and the World Bank (Wang, Alkire,2008; Zou, Fang, 2011; Khan, Saboor, et al, 2013; Monoya and Teixeira, 2017).

Nevertheless, there remains a great deal of work to do in the development and application of multidimensional poverty measures. On the one hand, the choice of dimensions, deprivation and poverty cutoffs and particularly the weights are still unfamiliar to many, and at present challenging to justify in the measurement of multidimensional poverty. What's more, the data often do not provide the variables on all dimensions desired in the calculation of MPI. On the other hand, although the outcome of robust test in Alkire and Santos (2014) shows that the rank of countries according to the global MPI is robust across the different weighting structures, a national MPI constructed using different indicators for one country may not be stable under different weighting structures. In theory, imposing a larger weight for one indicator will make the MPI more sensitive to the change of that indicator. A key question for the MPI, is how sensitive it is to different weighting structures in practice. And indeed how sensitive is it to using a 'zero' weight on some indicators - by excluding them altogether. Building on previous literature, this paper aims to illustrate new and fine-grained robustness techniques that can be used when the data sources 
are not representative by a large number of population subgroups. It also empirically provides new analyses of MPI in China.

Hence, following the Alkire-Foster MPI identification and aggregation procedures, our paper first calculates and analyzes an approximation of China's global MPI multidimensional poverty using the CHNS dataset, and making use of its panel component to track the evolution of poverty over time. Different from those researches on China's Multidimensional poverty Measurements (Labar and Bresson,2011; Yu, J. 2013; Zou and Fang, 2011), first, our paper studies the dynamics of China's multidimensional poverty, income poverty and their differences from 1989 to 2011 based on CHNS data. Second, this paper makes a stability analysis on multidimensional poverty with different combinations of weights and indicators in individual level, it's different from sensitive analysis in Alkire and Santos (2014) where its rank analysis is based on countries or regions with different weights. Third, although Wang, Feng, et al. (2016) had given a comparison analysis on multidimensional poverty with income poverty, but it's just one year data, our paper studies their differences with a long period which can help us to find a dynamic change in their differences and provide us more information for our analysis on these differences.

We then test the stability of multidimensional poverty measures under different combinations of weights and indicators. First our paper replicates a set of robustness tests that are similar to Alkire and Santos (2014) but more extensive in the set of weights tested. Also, in a novel methodological step, our paper constructs robustness tests at the level of the person, trialing an approach to robustness tests that would be applicable even for datasets that cannot be disaggregated by many population subgroups. Our paper also tests the stability of multidimensional poverty measures with the adjusted first-order stochastic dominance (FOSD) method and by calculating the rank correlation coefficients. As far as we know, FOSD is widely used in the sensitivity test of inequality and poverty measurement (Davidson and Duclos,2000; Duclos and Makdissi, 2005). Duclos et al. (2006) and Foster et al. (2013) undertake a 
theoretical analysis on the robustness of multidimensional poverty measures. Alkire et al. (2015) also mention that we can use FOSD method to test the sensitivity of MPI with choice of poverty cutoffs. The FOSD method proposed in this paper is different from the traditional construction. Here, we cumulate the proportion of MPI poor in ascending order of their income. The advantages of this construction are that, it can be used to observe the differences within and between each measure. It can also be used to see clearly the differences of multidimensional poverty among different income groups.

Subsequently, we compare multidimensional poverty measures with income poverty measures. Due to the different attributes owned by income and indicators in multidimensional poverty measures, the poverty identified by multidimensional measures are expected to be different from the poverty identified by the income method. Moreover, Banerjee and Duflo (2011) found that some income poor people would rather buy television or a cellphone than buy food for enough nutrition or take cheap immunizations for their children. So the behavior of income poor people will also make income poverty different from the multidimensional poverty and finally affect the efficiency of poverty reduction policy. As our paper shows, although both income poverty and multidimensional poverty have decreased significantly over time, multidimensional poverty is less volatile and its decline is more persistent. The rank in multidimensional poverty among provinces also differs from the income poverty ranking, and does not have a consistent order over the time. The deprivations in schooling, nutrition, sanitation, drinking water and cooking fuel are still considerable, particularly in China's rural areas.

Finally, this paper uses the panel logit regression model to compare the characteristics of each measure. The outcome shows that the multidimensional poverty measures built using different parameters have a certain consistency each other although there are some subtle differences. However, multidimensional poverty results are notably different from those of income poverty on the characteristics of household. 


\section{The construction of multidimensional poverty index (MPI)}

The construction of multidimensional poverty index involves the choice of identification strategies, aggregation procedures, dimensions and weighting structures. For the identification and aggregation procedures, our research uses the Alkire-Foster MPI calculation methodology, because the generalized form of aggregation methods in Bourguignon and Chakravarty (2003) have steep data requirements and also require us to determine the substitution elasticity between different dimensions, which is very difficult to do.

\subsection{Methodology}

Assume there are $n$ individuals, each individual is denoted by $i$ with $i=1, \ldots, n$; $d$ dimensions, each denoted by, $j$ with $j=1, \ldots, d$. Let $a_{i j}$ be the achievement of individual $i$ in dimension $j$. Let $w_{j}$ be the weight for dimension $j$ and $\sum_{j=1}^{d} w_{j}=1$. We denote by $z_{j}$ the deprivation cutoff for dimension $j$ which is defined as the minimum achievement required in order for an individual to be non-deprived. Finally, let $k$ be the "poverty cutoff", which identifies a household as multidimensionally poor, where $0<k \leq 1$. Then as is well known, we can construct the $M_{0}$ or MPI in three steps (Alkire and Foster, 2007, 2011):

First, calculate the deprivation status of each person for each dimension $g_{i j}$. If the $a_{i j}$ is less than $z_{j}$, then individual $i$ is deprived in $j$ dimension, so $g_{i j}=1$, otherwise, $g_{i j}=0$. Collect the deprivation status values in an $n$ by $d$ deprivation matrix $\mathrm{g}^{0}$.

Second, calculate the deprivation score of each individual and denote it $c_{i}$ where $c_{i}=\sum_{j} w_{j} g_{i j}$. If $c_{i}$ is less than or equal to $k$, then individual $i$ is multidimensionally poor. Censor the matrix $\mathrm{g}^{0}$ by replacing with the value zero any deprivations of people not identified as poor, and denote it $g^{0}(k)$. Similarly censor the vector of deprivation scores such that if a person is poor $c_{i}(k)=c_{i}$, otherwise, $c_{i}(k)=0$. 
Finally, calculate the multidimensional poverty index $M_{0}$ or MPI. $M_{0}$ is equal to the average of the censored deprivation scores: $M_{0}=\frac{1}{n} \sum_{i} c_{i}(k)$.

Assume that there are $q$ individuals who are identified as multidimensional poor by using the dual-cutoff approach, then we can rewrite the MPI as: $\left.M_{0}=\frac{q}{n} \llbracket \frac{1}{q} \sum_{i} c_{i}(k)\right]$. As is well known, $H=\frac{q}{n}$ is multidimensional poverty incidence. We define $A=\frac{1}{q} \sum_{i} c_{i}(k)$ as the average deprivation score, which is the intensity of poverty. Thus, $M_{0}=H \square A . M_{0}$ is the first measure in the Alkire-Foster class of measures. We choose $M_{0}$ for this analysis, because it can be used with ordinal, ordered categorical or dichotomous variables if the deprivation cutoff is fixed.

$M_{0}$ has many useful properties for analysis which are documented elsewhere (Alkire and Foster 2011, 2016; Alkire, Foster, Seth, Santos, Roche and Ballon, 2015). We draw particularly on subgroup decomposability in this paper. Assume the entire population is divided into $m$ mutually exclusive and collectively exhaustive groups. Then the overall $M_{0}$ can be expressed as a weighted average of the $M_{0}$ values of $m$ subgroups, where weights are the respective population shares. We denote the population, and the adjusted headcount ratio $M_{0}$ of subgroup $l$ by $n^{l}$ and $M_{0}^{l}$, respectively. Then the overall $M_{0}$ can be expressed as:

$$
M_{0}=\sum_{l=1}^{m} \frac{n^{l}}{n} M_{0}^{l}
$$

This feature is very useful for understanding the contribution of different subgroups to the overall poverty. Note that the contribution of a subgroup to the overall poverty depends both on the poverty level of that subgroup and that subgroup's population share. 


\subsection{Discussions on dimensions and weighting}

\subsubsection{The choice of dimensions}

The choice of indicators is restricted by the data survey. If the data is unavailable or the quality of data is poor, then the multidimensional poverty measurement becomes impossible or unbelievable. At the same time, we should consider two other rules: comparability and representativeness. Comparability means that the choice of dimensions must be internationally or nationally comparable. Representativeness requires that the dimensions are locally representative. While the representativeness may contradict with the comparability. For example, the drinking water, sanitation facility or cooking fuel may be not a problem to urban population, but it will be a severe problem in rural areas in China. People in China's urban areas mainly focus on accommodation, choice of school for children, environment quality, decent jobs, and so on. In addition, many dimensions correlated each other which makes the aggregation of all dimensions complicated. But if you ignore some dimensions, you may evaluate the poverty biasedly. Alkire, Foster, et.al (2015) construct an index to measure whether one indicator is redundant or not, if it is redundant, it can be dropped, unless it is retained for policy or some other reasons.

\subsubsection{Weighting}

The dimensional values or weights play an important role in multidimensional measures (Njong and Ningave,2008; Decancq and Lugo, 2013; Foster McGillivray and Seth, 2013; Alkire et al 2015, Ch.6), as they create cardinal comparability across. Decancq and Lugo (2013) categorized weighting strategies in three classes: Data-driven, normative and hybrid. Data-driven weights are a function of the distribution of the achievements in the society and are not based, at least explicitly, on value judgements about how the tradeoffs between the dimensions should be. Examples of these include frequency weights and statistical weights such as principal component analysis, factor analysis, multivariate analysis, regression analysis. Note however that Alkire et al 2015 draw attention to the multiple and often unjustified 
choices that are made in selecting 'data driven' weights. If these are used, at a minimum the results should document the sensitivity of the final measure to variation in the methodology of deriving statistical weights. Decancq and Lugo include normative weights examples such as equal weights, expert opinions, and prices. Normative weights depend on the value judgements about the tradeoffs and are not based on the actual distribution of the achievements in the society under analysis; And the last, hybrid approaches are both data-driven and depend on some form of valuation, such as self-reported rankings of dimensional importance, or hedonic values.

As Decancq and Lugo (2013) argue, there are advantages and disadvantages in using each weighting structure. Data- driven weights are claimed to be objective, but since they are generated from the data, they may have little economic or social intuition so be difficult to justify. When more than one computational avenue exists and the resulting weights lead to different conclusions, it can be difficult to explain which one is more reasonable. In section 3.4 of Alkire et al. (2015), different computational avenues are articulated, such as whether to use Principal Components, Factor Analysis, or Multiple Correspondence Analysis; if PCA for example, whether to use the correlation or covariance matrix; how many factors to retain; and how to aggregate and standardize these to create the final vector of deprivation scores. While earlier, since Lionel Robbins economics had sought to avoid making value judgements perhaps believing these to be un-justifiable - more recently there is a wider recognition that value judgements cannot be avoided; indeed that they are involved in the identification or determination of what is a fact (Putnam 2004). Sen (1967) also shows how that, someone disputing a value judgment put forward by someone else can have a scientific discussion on the validity of the value judgment by examining the scientific truth of the underlying factual premises.

Most MPIs to date use normative weights. It may seem difficult to choose a weighting vector that will be widely accepted, but in practice, the situation has clarified considerably. First, there is no need to panic when normative weights are required. As 
Sen argued: "A choice procedure that relies on a democratic search for agreement or a consensus can be extremely messy, and many technocrats are sufficiently disgusted by its messiness to pine for some wonderful formula that would simply give us ready-made weights that are 'just right.' However, no such magic formula does, of course, exist, since the issue of weighting is one of valuation and judgment, and not one of some impersonal technology.” (Sen 1999:79)

Empirical applications of multidimensional poverty measures have chosen a normative weighting structure, and much can be learned from these prior applications and the discussions and processes that generated and justified them. Also, as Alkire et al. (2015) stress, for multidimensional measures that will shape policy, it is essential to apply sensitivity analysis for weights and to ensure that the final measure is not unduly sensitive to the class or range of weights that could be considered reasonable by different groups of the population. In this way the final measure can be widely accepted and gains legitimacy. This paper, indeed, will propose a new methodology for assessing the robustness of MPI to alternative weighting structures.

\section{Data, the choice of dimension and weight}

\subsection{Data sources}

The main dataset used is the China Health and Nutrition Survey(CHNS). CHNS is an ongoing open cohort, international collaborative project between the Carolina Population Center at the University of North Carolina and the National Institute for Nutrition and Health at the Chinese Center for Disease Control and Prevention (CCDC). It is designed to examine the effects of the health, nutrition, and family planning policies and programs implemented by national and local governments and to see how the social and economic transformation of Chinese society is affecting the health and nutritional status of its population ${ }^{3}$. Up to now, there are nine rounds survey in CHNS, which were carried out in the years 1989, 1991, 1993, 1997, 2000, 2004, 2006, 2009, and 2011, respectively. Thus, we can use this longitudinal panel

\footnotetext{
${ }^{3}$ The sources and introduction of data are from CHNS website. Link.
} 
data to analyze the dynamics and transitions of China's multidimensional poverty.

The CHNS covers nine Chinese provinces that vary substantially in geography and economic development, including Liaoning, Heilongjiang, Jiangsu, Shandong, Henan, Hubei, Hunan, Guangxi, and Guizhou. These nine provinces have a strong regional representativeness, where, Liaoning and Heilongjiang are in the northeast part of China which are the representative of old-industrial base of China; Jiangsu and Shandong are in the east part of China which have a highly developed economy, especially since the implementation of reform and opening-up policy; Henan, Hubei and Hunan are located in the middle part of China, they are traditional agriculture areas, and in recent few years, these three provinces develop rapidly with policy support from central government, but regions within these provinces still develop unevenly; Guangxi and Guizhou are in the southwest of China where are mountain areas with backward economy. So while not nationally representative, the CHNS gives a good picture of the diversity of poverty conditions in different regions of China.

A multistage, random cluster process was used to draw the samples surveyed in each of the provinces. Counties in the nine provinces were stratified by income (low, middle, and high), and a weighted sampling scheme was used to randomly select counties in each province. Villages and townships within the counties, and urban and suburban neighborhoods within the cities were selected randomly. From 1989 to 1993,there were 190 primary sampling units: 32 urban neighborhoods, 30 suburban neighborhoods, 32 towns (county capital cities), and 96 rural villages. Since 2000, the primary sampling units have increased to 216: 36 urban neighborhoods, 36 suburban neighborhoods, 36 towns, and 108 villages. There are about 4,400 households in the overall survey, covering some 19,000 individuals. Follow-up levels are high, but families that migrate from one community to a new one are not followed. Movement within the primary sampling units and some larger urban entities is attempted ${ }^{4}$.

Figure 1 Map of CHNS survey regions in China

\footnotetext{
4 The introduction of sampling procedure is from CHNS website. Link.
} 


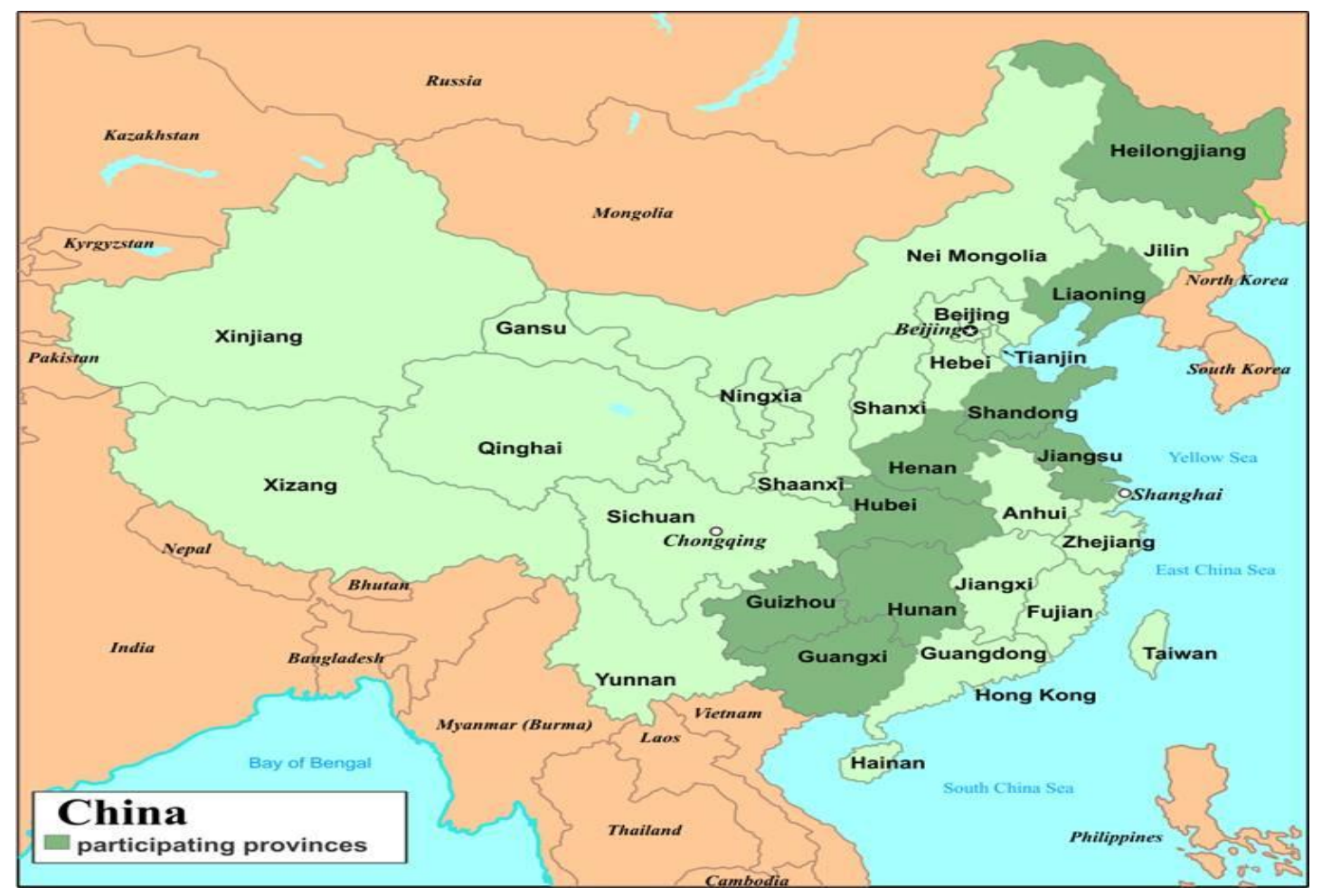

Source:The figure is from the CHNS website. Link.

\subsection{Dimensions and cutoff}

The choice of dimensions is not easy, but very important. Based on capability approach, the potential dimensions for poverty measurement are abroad and include education, health, living standards, and work, empowerment, environment, safety from violence, social relationships, culture and so on (Alkire 2007,2008). But due to the data constraints of the survey data available for over 100 countries, UNDP and the Oxford Poverty and Human Development Initiative (OPHI) only chose health, education and living standards to calculate the global MPI. Following them (Alkire and Santos 2014), this paper also chooses these three dimensions. Although CHNS has both adult and children surveys, it is difficult to measure the intra-household distribution and to distinguish individual poverty within the household. Thus, we use the household as the unit of identification: that is, we use the information of all household members to identify whether the household and all its members are poor or not.

In each dimension, this paper selects indicators that replicate insofar as is possible the global MPI. For education, this paper uses two indicators: whether someone in the 
household has at least five years of education and whether all children of school age are attending school ${ }^{5}$. All household members are considered non-deprived if at least one person has five years of schooling or more. School attendance is used to indicate whether children, at the age in which they would attend classes one to eight, are being exposed to a learning environment. This indicator is used in the Millennium Development Goals (MDGs) and UNESCO (2010). When a school-age child is not in school, all household members are considered as deprived.

This paper mainly uses two type of health indicators: whether any member in household is undernourished and whether any child is died in the household. Under-nutrition usually indicates a functioning failure which can have life-long effects in terms of cognitive and physical development in the case of children and which make any person vulnerable to other health threats. We use the BMI-for-age to evaluate the nutritional status for people whose age are more than 5 years old, and use weight-for-age for children whose age are between 0 and 5 years old, in both cases following the standards set by the $\mathrm{WHO}^{6}$. Another indicator for health is whether any child is died in the household. The death of a child is a total health functioning failure that influences the entire household (Alkire and Santos, 2014). So all members are considered deprived if there has been at least one observed child death (of the age) in the household. Since CHNS have 9 waves of survey with a period of 22 years, we consider household as poor if household has some child died in the year between last round survey and this round survey. Thus our indicator differs from the global MPI that considers all child deaths within the last five years. In year 1989, we consider household as deprived in the mortality if the household experienced a child death between year 1985 and year 1989. In the stability analysis, we also use self-reported health to substitute the BMI-for-age as health indicator to calculate the MPI for

\footnotetext{
5 In China, although the compulsory education law is issued in 1986, but there is no uniform time to change the years of primary education from 5 years to 6 years for different regions. Hence, the cutoff for the years of education follows some important Chinese multidimensional poverty researches, such as Wang and Alkire (2008); Zou and Fang (2011) and so on.

6 The reference and Stata computation procedures are from WHO. Link.
} 
technical reasons. We recognize that self-reported health data may reflect adaptive preferences, and may be affected by other influences such as telescoping, mood, frame of reference, and personality type, but use it mainly to illustrate a particular technique, due to the lack of better data. The data of self-reported health indicator are only recorded from 1997 to 2006 in the CHNS and we consider the household as health poor when at least one member in household reports that their health are poor.

The standard of living dimension of the global MPI comprises six indicators: sanitation, drinking water, electricity, floor, cooking fuel and assets. Sanitation, drinking water and cooking fuel were three standard MDG indicators. Not having clean drinking water and cooking fuel and an improved sanitation facility are harmful for health (UN, 2003). Poor water quality and sanitation are a leading cause of mortality and disease in developing countries. For example Duflo, et al (2015) also find that an integrated water and sanitation improvement in rural India reduced treated diarrhea episodes by $30-50 \%$, and their results held in both the short term and long term. Electricity and flooring material provide some rudimentary indication of the quality of housing. The last indicator is asset, which covers the ownership of some consumer goods, including television, telephone, refrigerator, electric fan and air conditioner, bicycle, motorbike, car and truck (not radio). All these are durable goods. With technological advancement, some consumer goods have changed, such as television and telephone, thus we consider a household has a television if it owns a black/white TV or color TV, and has a telephone if it owns a telephone or cellphone. Before 1993, there are no records of telephones and cellphones in household survey. In calculation of the asset poverty, we must unfortunately treat all households as non-deprived in telephone before 1993.

The living standard indicators are means rather than ends, they are not direct measures of functioning. Yet, these means are very closely connected with the ends (functioning) they are supposed to facilitate. In CHNS, the data of flooring material are missing in the wave of 2009 and 2011.Thus, we will use MPI excluded the flooring material. Also, because the rate of child mortality since the last survey is very low, we will not 
include child mortality in the MPI when we do decomposition analysis by regions, stability analysis on the change of weights and comparison analysis with income poverty.

Finally, our paper also uses the income data to calculate income poverty, and compare it with multidimensional poverty. We choose the household income, and use income per capita to calculate the individual income, and inflate all these individual income to 2011 price with price index which varies with regions and times. China's rural national poverty line was RMB 2300 per person in year 2011.Because CHNS includes the regional-adjusted and year-adjusted price index, and the income is adjusted by this price index, so we also directly use RMB 2300 as the urban poverty line to calculate urban income poverty.

Table 1 Dimensions, indicators and cutoffs of the CHNS-based global MPI

\begin{tabular}{|c|c|c|}
\hline Dimensions & Indicator & Deprived if \\
\hline \multirow[t]{2}{*}{ Education } & Years of Schooling & No household member has completed five years of schooling \\
\hline & Child Attendance & Any school-aged child is not attending school in years 1 to 8 \\
\hline \multirow[t]{2}{*}{ Health } & Mortality & Any child has died in the family since the past survey period \\
\hline & Nutrition & $\begin{array}{l}\text { Any Adult or child for whom there is nutritional information is } \\
\text { malnourished }\end{array}$ \\
\hline \multirow{6}{*}{$\begin{array}{l}\text { Living } \\
\text { Standard }\end{array}$} & Cooking Fuel & The household cooks with straw, wood, charcoal, etc. \\
\hline & Sanitation & The household has cement open pit, earth open pit or no bathroom. \\
\hline & Drinking water & $\begin{array}{l}\text { The source of drinking water is open well (less than } 5 \text { meters), creek, } \\
\text { spring, river etc. or safe drinking water is more than } 30 \text { minutes } \\
\text { walking from home, roundtrip }\end{array}$ \\
\hline & Electricity & The household has no electricity \\
\hline & Floor & The household has a dirt, sand or dung floor \\
\hline & Assets & $\begin{array}{l}\text { The household does not own more than one of the following assets: } \\
\text { television, telephone, bicycle, motorcycle, tricycle, refrigerator, and } \\
\text { does not own a car or a truck. }\end{array}$ \\
\hline
\end{tabular}

Note: In UNESCO (2010), China's school-aged children are defined as whose age are from 6 to 14 although see Alkire and Shen who use 7-15. Nutrition deprivation standard: Children (0-5 years old) are considered malnourished if their z-score of weight-for-age are below minus two standard deviations from the median of the reference population. Children (5-19 years old) are considered malnourished if their z-scored of BMI-for age are below minus two standard deviations from the median of the reference population, Adults are considered malnourished if their BMI are below 18.5. All the information and algorithms are provided by the WHO. 


\subsection{Missing data and sample size}

In our paper, we merge the household level datasets with individual level datasets. If the information of all household level indicators for multidimensional measurement are missing, then this household will be excluded. Information missing in the household datasets is not very severe, the proportion of missing data in each dimension is very small ${ }^{7}$. In the individual datasets, the missing information mainly does not affect our poverty identification on household. If individual's household ID does not belong to the household survey datasets, then we delete this observation. Hence, the outcomes of multidimensional poverty measures are underestimated following our procedure, especially in 1989. But the bias is not very large except for 1989.

The treatment of some specific indicators differs marginally from the global MPI specifications set out in Alkire et al. (2016) and the references therein. First, in years of schooling, if data of this household includes at least one member who has five or more years of education, then we classify this household as non-deprived even if others are missing. Second, if the nutritional information of all household members was missing, we consider the household as missing in this indicator, otherwise, we use the available information.

In order to reduce the loss of sample and keep the sample size as big as enough, we keep all observations in each wave, even though this means the panel is unbalanced ${ }^{8}$. The longitudinal data also could be used to analyze the dynamics and transition of household multidimensional poverty. Finally, the total sample size left after our processing is 36434 households, 132313 individuals for nine wave surveys. There are $3788,3605,3421,3826,4285,4329,4368,4427,4385$ households included in each year, respectively, and 15897, 14730, 13822, 14314, 15436, 14310, 14745, 14685, 14374 individual respondents in each year, respectively.

\footnotetext{
${ }^{7}$ For the original household-level data, the proportion of missing data is below $1 \%$ for each dimension. ${ }^{8}$ We also processed the data into panel data and made a simple comparison analysis in the following part. After processing, there were 1537 household samples left each year for panel data.
} 


\subsection{Poverty cutoff}

The indicators with their deprivation cutoffs have been computed, the next step is to determine who is multidimensionally poor. Thus, we have to set the poverty cutoff. There are two extreme possibilities, which are called the union approach and intersection approach, respectively. For the union approach, if the household is deprived in at least one indicator, then it is identified as multidimensionally poor. For the intersection approach, only if the household is deprived in all indicators do we regard this household as multidimensionally poor. The general poverty cutoffs are between these two extreme cases, and the number of poor persons they will identify is also between these two cases. The union approach is so strictly that it does not accurately establish that a person is multidimensionally poor. For example, a person may have not enough education, but he /she has a good health, lives in a great house with flush toilet and has a car, whatever, we may not think this person is in poverty. In the global MPI, each person is identified as multidimensionally poor if and only if they are deprived in at least one-third of the weighted indicators. In most of our calculations, we choose $33.33 \%$ as the poverty cutoff. We later apply robust tests for a range of poverty cutoffs in the stability analysis.

\section{Measurement outcomes}

\subsection{The headcount ratio of dimensions in different years}

In the table 2, we can find that the headcount ratio of most of indicators decline very quickly. In the economic variables, asset deprivations follow the trend of income poverty, Asset deprivation incidence drops from $28.9 \%$ in year 1989 to $2.71 \%$ in year 2011 and income poverty incidence drops from $42.5 \%$ to $12.4 \%$. Sanitation facility deprivation is the most severe among all the indictors, although its deprivation ratio drops sharply by 27.4 percentage points from year 1989 to year 2011, but in year 2011, there are still $35.1 \%$ households deprived of this indicator, and most of sanitation-deprived households are living in the rural area. The deprivation of drinking water and cooking fuel are similar to sanitation: the incidence drinking water 
deprivations declines from $29.4 \%$ in year 1989 to $8.19 \%$ in year 2011, the headcount ratio of cooking fuel deprivations declines from $35.8 \%$ to $16.0 \%$.

In the most of China's rural areas, because of history customs, local resources and lower costs, people mainly cook with wood or agricultural residues or coal in some places, drink the water from shallow wells or pond or rivers, and use open pit latrines and apply temporary stored human excreta from open pit latrines as fertilizers to enrich their farmlands, which make the rural area more likely to be deprived in these indicators. But according to rural people's own evaluation of deprivation, they may not think that they are deprived in these indicators. Although the Chinese government has already made great efforts to improve these indicators for rural areas and acquired a great achievement, agreement between the government and rural people as to appropriate indicators of deprivation will be also an important issue to solve in near future in China's rural areas.

For the dimension of education, the deprivation ratio of child attendance drops quickly and is at a very low level in recent years. But the deprivation of years of education gets worse after year 2000, its deprivation ratio is $7.77 \%$ in year 2000, and is the lowest in all the years. Then its deprivation ratio unexpectedly increases to $10.7 \%$ in 2004 , to $13.7 \%$ in 2006 , after year 2006 , it stays above $12.5 \%$. If we decompose the years of school by rural-urban, we can find that, the increase mainly comes from rural areas after 2006, the deprived proportion increases from $10.9 \%$ in year 2004 to $15.5 \%$ in 2006, and then stays above 14\%. But in urban areas, the deprived proportion drops from $10.2 \%$ in year 2004 to $8.31 \%$ in year 2011.It means that the education continues to deteriorate in rural areas, and the education inequality between rural areas and urban areas widens over time. There are two reasons for this phenomenon: First, in China, education is the main route to get rid of identity 'farmer' for rural population, so most of people who acquire higher education move out of village to city. Second, because of household registration (hukou) system which creates a large number of 'left-behind' children. These 'left-behind' children live in an environment with scarce and poor education resources and with no right behavior 
restriction from their grandparents who left in village to take care of them. After a period of time, most of these left-behind children are eliminated from the school by Chinese cruel education race. Even those children could study in the city with their parents, their families need pay for a large amount of temporary education fee or they need go to some special schools for those migrant children where the quality of facilities and teachers are also very poor. All of these expand the rural-urban education inequality.

The proportion of household who has ever had a child died declines from $1.74 \%$ in year 1989 to $0.023 \%$ in year 2011: a great improvement in relative terms, although as mentioned below given the sample size child mortality is no longer an appropriate indicator for health deprivation. And the proportion of household who has some members malnourished also drops from $25.6 \%$ in year 1991 to $12.4 \%$ in year 2011.But 12.4 percent is still a very high level. Through the decomposition of this indicator by rural-urban areas, it is easy to find that malnutrition is more severe in rural areas. All of these illustrate that the health does not improve relatively as much as the great improvement seen in living standards, especially in rural areas. If we consider other health indicators, including mental health, disease, accidents or self-reported health, it seems likely to show that health is still a severe problem both in the rural areas and in the urban areas.

A note on data is required before proceeding. Although we have calculated the rates of deprivation in floor and mortality, we are not convinced that the apparent outcomes are accurate. First, the deprivation rate of flooring dropped sharply from 25.3 percent in year 1991 to 1.25 percent in year 1993. It would be very unusual to see such a transformation. Also, the data of floor material are missing in year 2009 and 2011. Second, for the child mortality, since CHNS is a long duration survey, this paper considers a household as deprived in mortality if the household has ever had any child died between the year of this survey and last survey. As the table 2 shows, only $0.64 \%$ households had at least one child between 1989 and 1991, and the rate continues to decline to $0.02 \%$ in year 2011 , which is not significantly different from zero given the 
sample size. In the most following calculation and analysis of MPI, we will drop floor material and child mortality and focus on the other 8 indicators except where otherwise indicated.

Table 2 The uncensored headcount ratio of each indicator in 1989-2011

\begin{tabular}{l|lllllllll}
\hline & 1989 & 1991 & 1993 & 1997 & 2000 & 2004 & 2006 & 2009 & 2011 \\
\hline Drinking water & 0.2940 & 0.226 & 0.205 & 0.129 & 0.135 & 0.120 & 0.117 & 0.0969 & 0.0819 \\
Sanitation & 0.625 & 0.587 & 0.588 & 0.536 & 0.520 & 0.475 & 0.444 & 0.370 & 0.351 \\
Electricity & 0.0715 & 0.0399 & 0.0149 & 0.00680 & 0.00863 & 0.00323 & 0.00321 & 0.00361 & 0.0103 \\
Cooking fuel & 0.358 & 0.384 & 0.381 & 0.361 & 0.282 & 0.257 & 0.218 & 0.165 & 0.160 \\
Flooring & 0.253 & 0.248 & 0.0111 & 0.0303 & 0.0140 & 0.0051 & 0.0009 & 0 & 0 \\
Asset & 0.289 & 0.241 & 0.186 & 0.133 & 0.0957 & 0.0700 & 0.0634 & 0.0440 & 0.0271 \\
Years of school & 0.115 & 0.0890 & 0.0848 & 0.0920 & 0.0777 & 0.107 & 0.137 & 0.125 & 0.131 \\
Child attendance & 0.0599 & 0.0383 & 0.0590 & 0.0209 & 0.0198 & 0.00116 & 0.00664 & 0.00542 & 0.00889 \\
Nutrition & 0.131 & 0.256 & 0.228 & 0.186 & 0.163 & 0.139 & 0.131 & 0.141 & 0.124 \\
Child Mortality & 0.0174 & 0.0064 & 0.0023 & 0.0050 & 0.0030 & 0.0039 & 0.0018 & 0.0016 & 0.0002 \\
Income & 0.4250 & 0.4430 & 0.4250 & 0.3120 & 0.259 & 0.225 & 0.214 & 0.123 & 0.124 \\
\hline Observations & 3788 & 3605 & 3421 & 3826 & 4285 & 4329 & 4368 & 4427 & 4385 \\
\hline
\end{tabular}

Note: The data of decomposition by rural-urban does not be shown in the table.

\subsection{The measurement of Multidimensional poverty}

In the measurement of multidimensional poverty, we use the equal weights for each dimension as a benchmark, that is, we allocate $1 / 3$ to each dimension: education, health and the living standard. And each indicator within each dimension are also allocated equal weights, replicating the nested weighting structure of the global MPI. The poverty cutoff is likewise $1 / 3$ or $33.33 \%$.

Table 3 shows that there has been a significant reduction in MPI from year 1991 to year 2011, whatever with 10 indicators or with 8 indicators. For 10 indicators, M0 declines from 0.0621 to 0.0104 , and for 8 indicators, M0 declines from 0.133 to 0.0529. Dropping flooring and child mortality does affect the levels of measured poverty but both still show a striking trend. Using nested weights with 10 indicators, the proportion of multidimensional poverty population declines from $15.7 \%$ in year 
1991 to $2.7 \%$ in year 2011. For nested weights with 8 indicators, the proportion of multidimensional poverty population is $29.4 \%$ in year 1991, and declines to $13.3 \%$ in year 2011.

As the figure 2 shows, according to both the 8- and 10-indicator MPIs, multidimensional poverty has reduced 1991-2011, although compared to the income poverty, the reduction of multidimensional poverty is more gentle. The income headcount ratio declined from $45.6 \%$ in 1989 to $14 \%$ in 2011 . We think this seems reasonable, because most of indicators in multidimensional poverty are permanent indicators, such as assets composited with durable goods, education and nutrition for adults, child mortality for households, and so on. But individual income always varies every year for every person, and is also easily affected by the social and economic environment. For example, unemployment affects the income, but may not change his education, health or asset immediately. Figure 3 shows the variation of MPI for different poverty cutoffs values and for three years. As is usual for such analyses, the MPI has a sharp drop across some range of values, particular here when the poverty cutoff is between 0.3 and 0.4 . It means that the MPI, $\mathrm{H}$ and $\mathrm{A}$ will change depending on the value of the poverty cutoffs but does not yet tell us about whether comparisons across subnational regions are sensitive to different poverty cutoffs.

Table 3 MPI, H and A with standard errors 1989-2011 for 8 and 10 indicators ${ }^{9}$

\begin{tabular}{|l|l|l|l|l|l|l|l|l|l|l|l|}
\hline & \multicolumn{4}{|l}{ Nested weights with 10 indicators } & \multicolumn{4}{l|}{ Nested weights with 8 indicators } \\
\hline & M0 & $\begin{array}{l}\text { Std. } \\
\text { Err. }\end{array}$ & $\begin{array}{l}95 \% \text { confidence } \\
\text { interval }\end{array}$ & H & A & M0 & $\begin{array}{l}\text { Std. } \\
\text { Err. }\end{array}$ & $\begin{array}{l}95 \% \text { confidence } \\
\text { interval }\end{array}$ & H & A \\
\hline 1989 & 0.0549 & 0.0023 & $(0.05040 .0594)$ & 0.137 & 0.4007 & 0.0882 & 0.0030 & $(0.08230 .0940)$ & 0.199 & 0.4441 \\
\hline 1991 & 0.0621 & 0.0024 & $(0.05730 .0669)$ & 0.157 & 0.3952 & 0.133 & 0.0036 & $(0.12650 .1405)$ & 0.294 & 0.454 \\
\hline
\end{tabular}

\footnotetext{
${ }^{9}$ Nested weight means that we allocate equal weights to each dimension and equal weight to indicators within each dimension. That is, nested weight with 10 indicators means the weight for drinking water, sanitation, electricity, cooking fuel, floor, asset, years of schooling, child school attendance, nutrition, and child mortality are 1/18,1/18,1/18,1/18,1/18,1/18,1/6,1/6,1/6,1/6,1/6 respectively. Nested weight with 8 indicators means the weight for drinking water, sanitation, electricity, cooking fuel, asset, years of schooling, child school attendance, and nutrition are $1 / 15,1 / 15,1 / 15,1 / 15,1 / 15,1 / 6,1 / 6,1 / 3$, respectively.
} 


\begin{tabular}{|l|l|l|l|l|l|l|l|l|l|l|}
\hline 1993 & 0.0364 & 0.0020 & $(0.03250 .0402)$ & 0.094 & 0.3863 & 0.118 & 0.0035 & $(0.11070 .1244)$ & 0.262 & 0.4483 \\
\hline 1997 & 0.0252 & 0.0015 & $(0.02220 .0283)$ & 0.067 & 0.3786 & 0.0902 & 0.0029 & $(0.08440 .0959)$ & 0.206 & 0.4373 \\
\hline 2000 & 0.0189 & 0.0013 & $(0.01640 .0214)$ & 0.050 & 0.3777 & 0.0771 & 0.0026 & $(0.07200 .0822)$ & 0.181 & 0.4269 \\
\hline 2004 & 0.0144 & 0.0011 & $(0.01220 .0166)$ & 0.038 & 0.3797 & 0.0637 & 0.0024 & $(0.05910 .0684)$ & 0.151 & 0.4213 \\
\hline 2006 & 0.017 & 0.0012 & $(0.01460 .0193)$ & 0.045 & 0.3778 & 0.0618 & 0.0023 & $(0.05730 .0664)$ & 0.146 & 0.4227 \\
\hline 2009 & 0.0105 & 0.0009 & $(0.00870 .0123)$ & 0.028 & 0.3716 & 0.0596 & 0.0022 & $(0.05530 .0639)$ & 0.150 & 0.3961 \\
\hline 2011 & 0.0104 & 0.0009 & $(0.00850 .0122)$ & 0.027 & 0.3782 & 0.0529 & 0.0021 & $(0.04880 .0570)$ & 0.133 & 0.3969 \\
\hline
\end{tabular}

Note: Nested weight means that we allocate equal weight to each dimension and equal weight to indicators within each dimension.

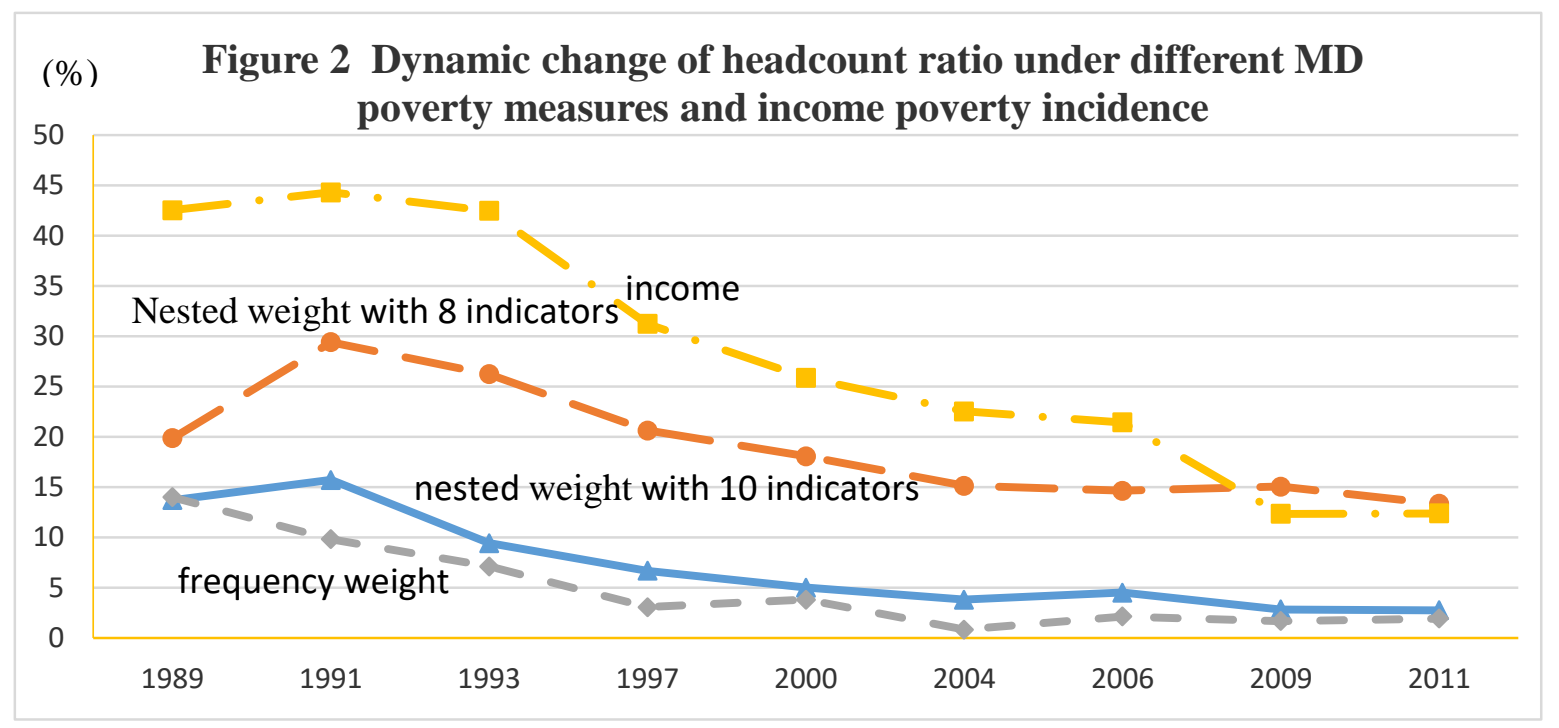

Note: Nested weight means that we endow equal weights to each dimension and equal weight to indicators within each dimension 


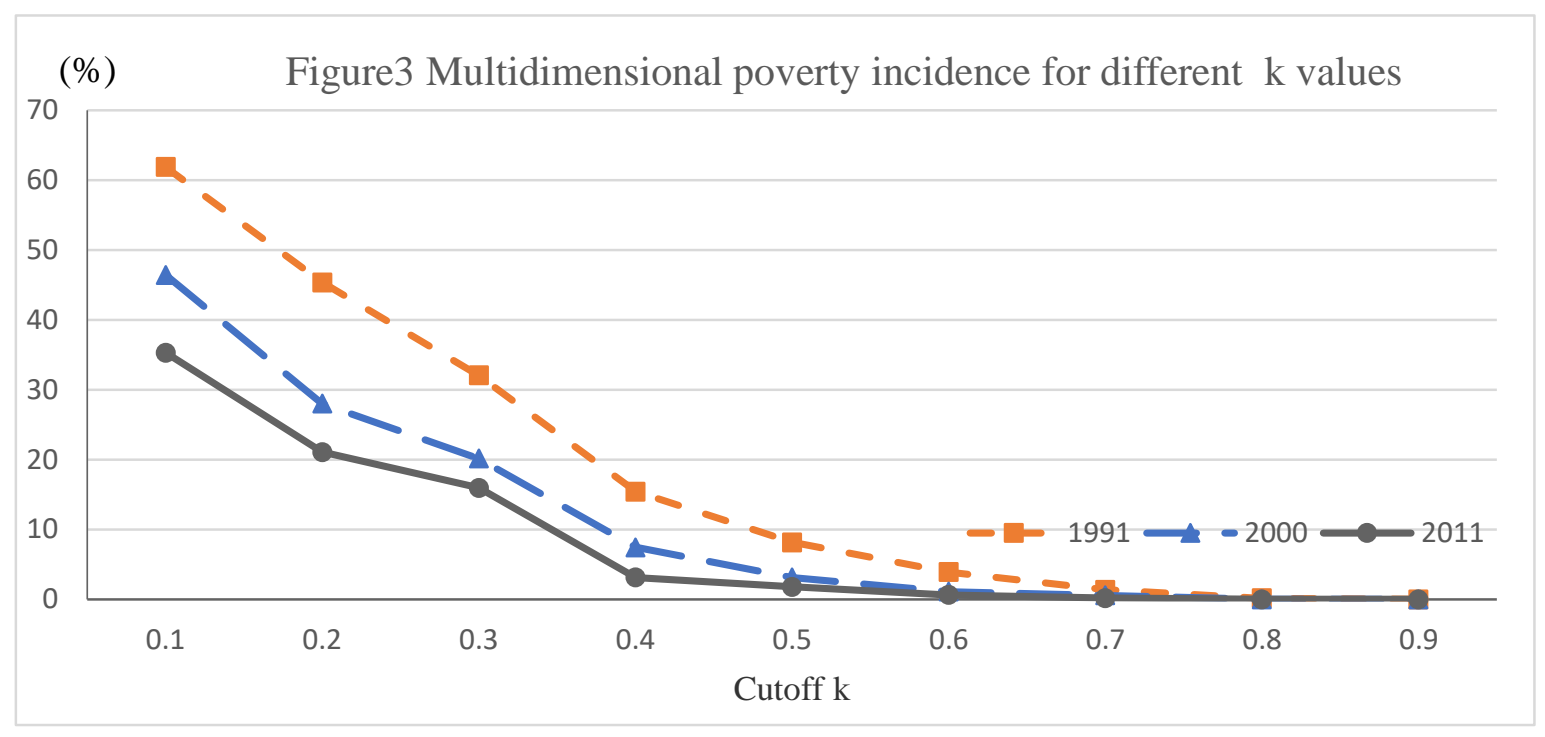

\subsection{The decomposition of MPI}

In order to further learn about the dynamic distribution of China's multidimensional poverty, we divide the MPI by the provinces and rural-urban areas. In the table 4 and figure 4 , we can observe the variation of multidimensional poverty of each region over time. First, both rural and urban areas have a statistically significant reductions in M0. The rural M0 declines from 0.155 in year 1991 to 0.0603 in year 2011. The change amounts to a decrease of $61.1 \%$ relative to the starting levels of poverty. The urban M0 declines from 0.0887 to 0.0373 . This change amounts to a relative decrease of $57.9 \%$. Second, as figure 4 shows, multidimensional poverty in rural areas is higher than in urban areas, and their difference is statistically significant. In 1991, the difference between urban M0 and rural M0 is 0.0663 , and rural M0 is $41.7 \%$ higher than urban M0, and in 2011, the difference is 0.023 , but rural M0 is $55.8 \%$ higher than urban M0. Thus, it means that, although the absolute difference of M0 between rural and urban declines over time, the rural area declines at a slower pace in M0, and so the relative difference between two areas widens over time.

Across the nine provinces, the multidimensional poverty in Shandong province is the lowest over the time, and Guangxi and Guizhou province are the highest over the time, and both the differences are statistically significant compared to the other provinces. 
What is interesting in the provincial comparisons, though, is that multidimensional poverty in other provinces is not very consistent with their economic development level. Henan and Liaoning follow Shandong sequentially with a lower multidimensional poverty, and then are Jiangsu, Heilongjiang and Hunan province. The multidimensional poverty in Henan province is much higher before 2000, then it declines rapidly and becomes the second lowest after 2006. The figure 5 shows that, Liaoning, Henan, Hubei and Guizhou have a significant and continuous decline in the multidimensional headcount ratio, but Guizhou still has a higher ratio in 2011, about 22.3\% . At the same time, Heilongjiang, Jiangsu, Shandong, Hunan and Guangxi are in slight oscillation around each steady ratio after 1997. Guangxi has the highest multidimensional headcount ratio and Shandong has the lowest ratio.

Hence, compared figure 5 with figure 6 , we can find that the rank of multidimensional poverty among the provinces is much different from their rank by income poverty. For income poverty, Jiangsu is the lowest one. Since the 9 provinces in CHNS cross the whole China from Heilongjiang in northeast to Guizhou in southwest, two are in northeast part of China, two are east developed provinces, three are located in the middle of China, and two are in the west of China, their living habitations are very different from each other, especially in rural areas. Multidimensional poverty is easily affected by these living habitation which makes us consider it as why the dynamics of multidimensional poverty of different provinces is not consistent with income poverty.

Table 4 Decomposition of MPI under nested weights with 8 indicators by province and urban

\begin{tabular}{llllllllll}
\hline & 1989 & 1991 & 1993 & 1997 & 2000 & 2004 & 2006 & 2009 & 2011 \\
\hline M0 & 0.0882 & 0.133 & 0.118 & 0.0902 & 0.0771 & 0.0637 & 0.0618 & 0.0596 & 0.0529 \\
\hline Rural & 0.105 & 0.155 & 0.134 & 0.108 & 0.0884 & 0.0741 & 0.0732 & 0.0696 & 0.0603 \\
Urban & 0.0536 & 0.0887 & 0.0808 & 0.0532 & 0.0533 & 0.0417 & 0.0377 & 0.0386 & 0.0373 \\
\hline Liaoning & 0.0402 & 0.0833 & 0.0725 & & 0.0601 & 0.0502 & 0.0367 & 0.0415 & 0.0319 \\
Heilongjiang & & & & 0.0677 & 0.0598 & 0.0472 & 0.0413 & 0.0504 & 0.0491 \\
Jiangsu & 0.117 & 0.107 & 0.128 & 0.0538 & 0.0529 & 0.0436 & 0.0505 & 0.0461 & 0.0457 \\
Shandong & 0.0400 & 0.0711 & 0.0551 & 0.0396 & 0.0312 & 0.0297 & 0.0273 & 0.0343 & 0.0225 \\
Henan & 0.0992 & 0.110 & 0.0934 & 0.0795 & 0.0522 & 0.0369 & 0.0375 & 0.0358 & 0.0317 \\
\hline
\end{tabular}




\begin{tabular}{llllllllll}
\hline Hubei & 0.0882 & 0.159 & 0.126 & 0.113 & 0.100 & 0.0724 & 0.0557 & 0.0477 & 0.0415 \\
Hunan & 0.0615 & 0.131 & 0.108 & 0.0710 & 0.0672 & 0.0575 & 0.0700 & 0.0632 & 0.0469 \\
Guangxi & 0.135 & 0.238 & 0.199 & 0.123 & 0.124 & 0.112 & 0.122 & 0.123 & 0.107 \\
Guizhou & 0.126 & 0.159 & 0.146 & 0.167 & 0.137 & 0.119 & 0.109 & 0.0881 & 0.0936 \\
\hline
\end{tabular}

Note: The whole table including MPI, standard error and $95 \%$ confidence interval is attached in the appendix table A1. The contributions of each region to total MPI are shown in the figure A1 and figure A2.

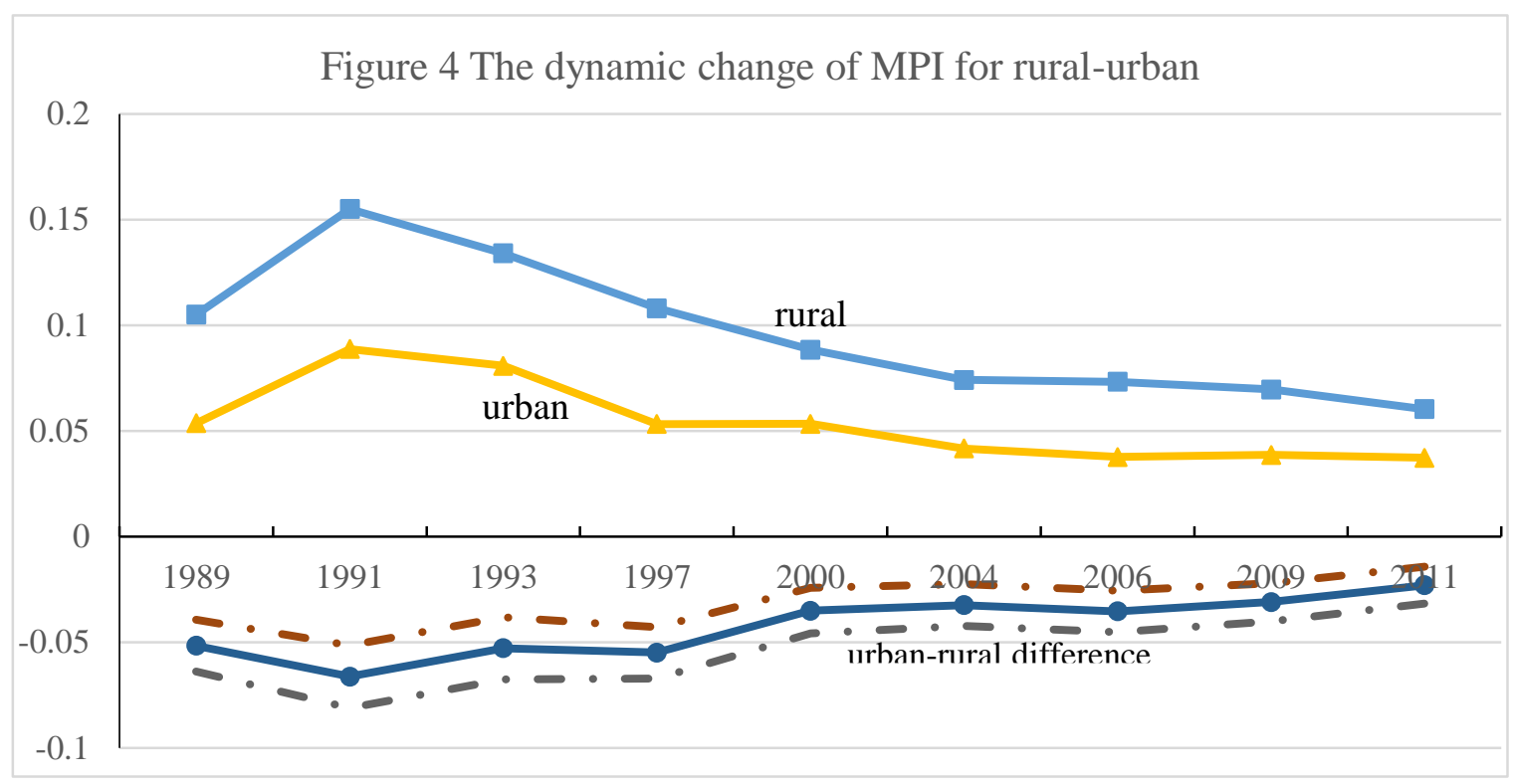

Note: The dash line is the graph of $95 \%$ confidence interval for the difference of MPI between rural and urban.

Figure 5 Dynamic change of multidimensional poverty by provinces

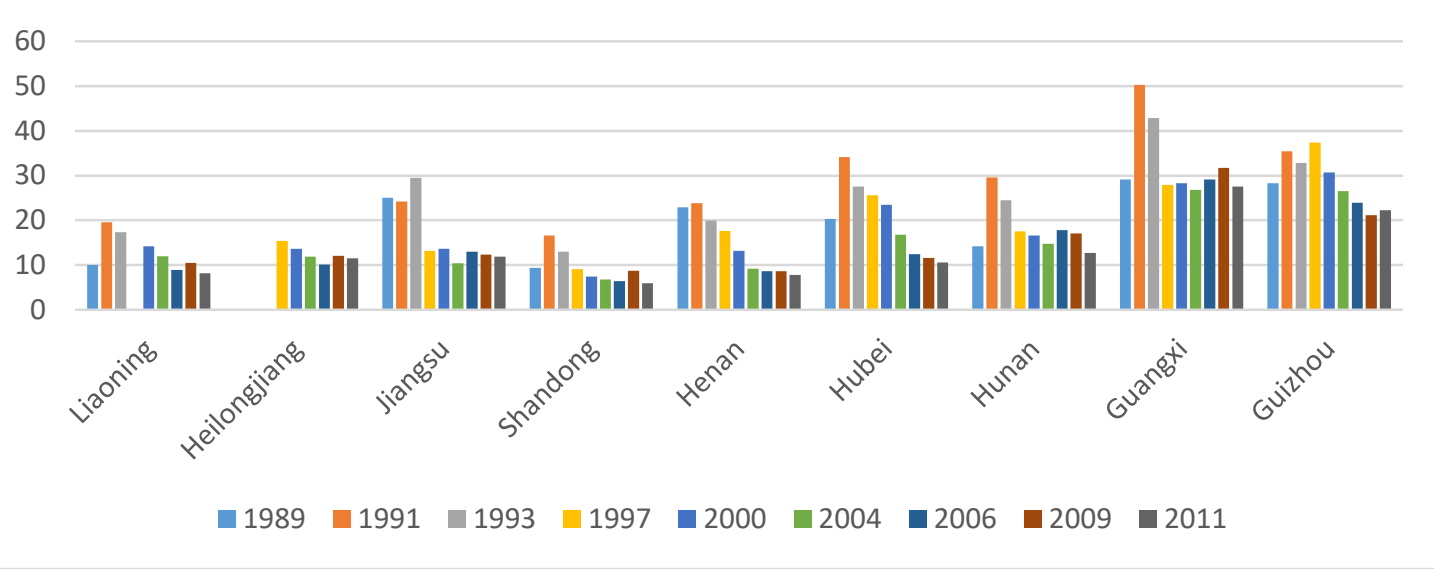


Figure 6 Dynamic change of income poverty headcount ratio by provinces

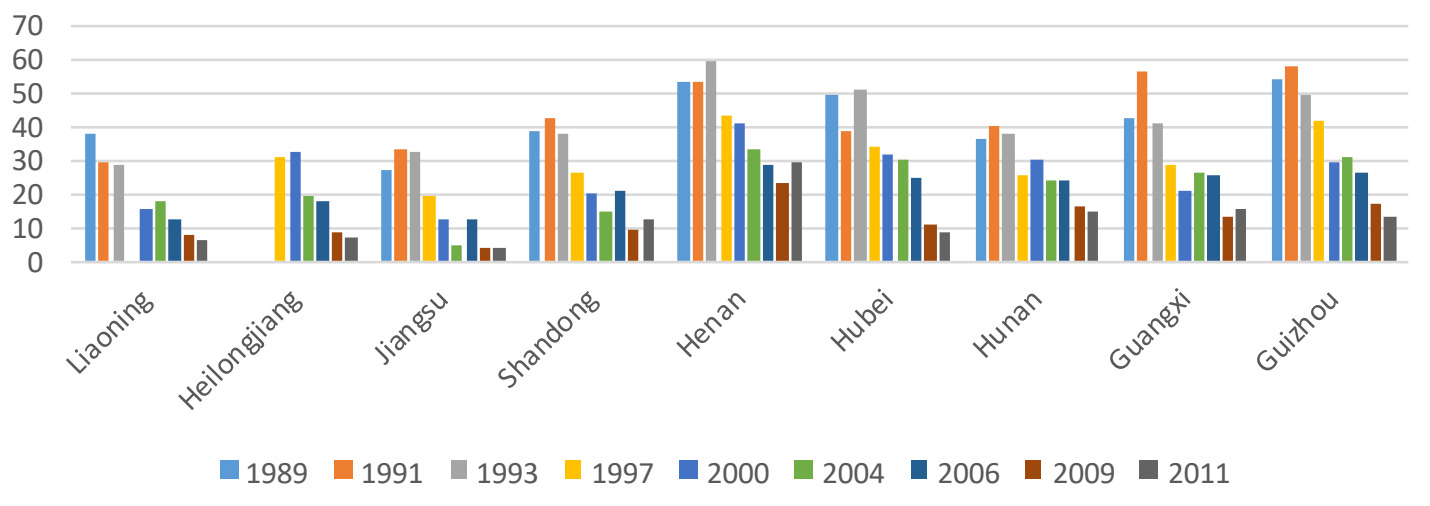

Figure 7 The headcount ratio of income poverty and MD poverty in 1991 and $2011(\%)$

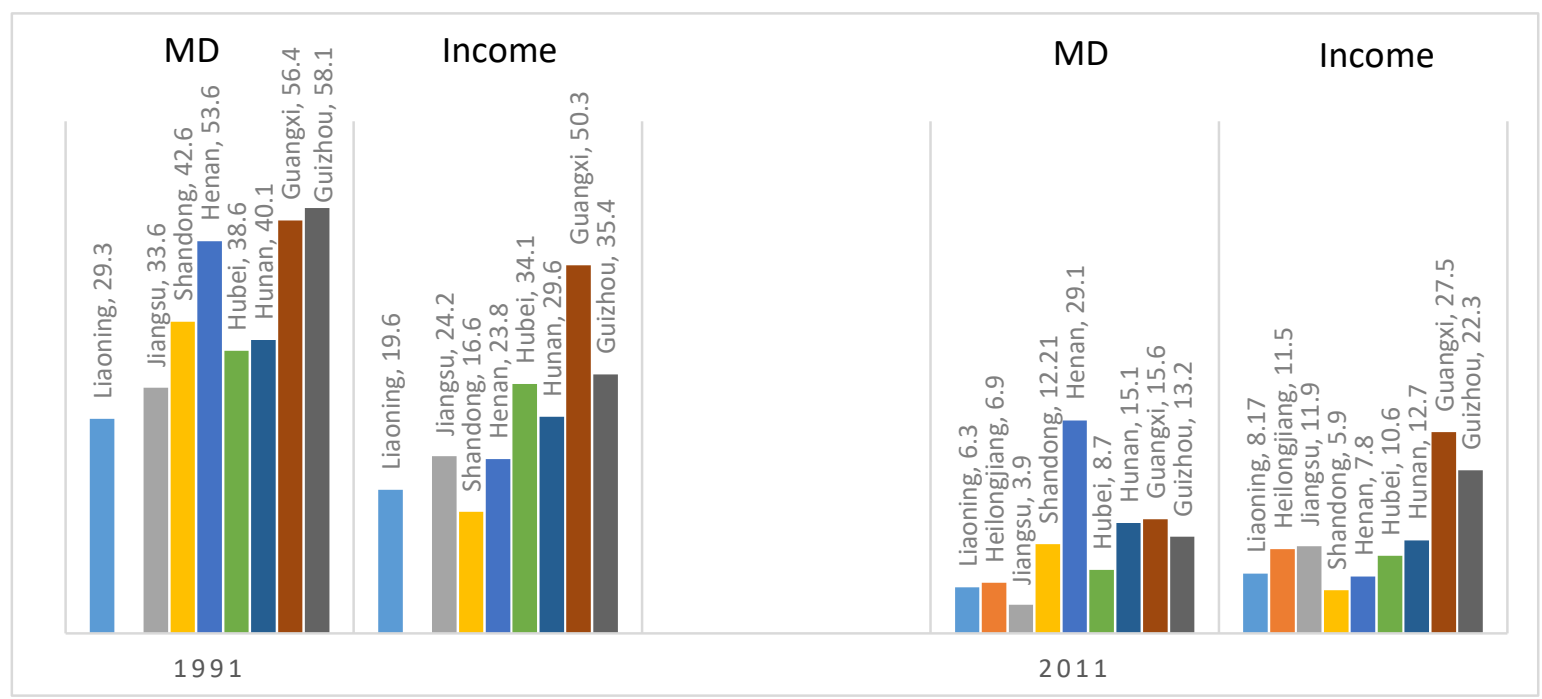

\section{Stability and Robustness analysis}

In order to test whether the MPI is robust to different weights, our paper also chooses four other alternative weighting structures. Following Alkire and Santos (2014), the first three weighting structures give $50 \%$ of the relative weight to one of the three dimensions and $25 \%$ to each of the other two in turn. In a fourth weighting vector, we use one kind of frequency weighting structure, and construct each indicator $j$ 's weight as follows:

$$
w_{j t}=\ln \left(1 / h_{j t}\right) / \sum_{j=1}^{d} \ln \left(1 / h_{j t}\right)=\ln h_{j t} / \sum_{j=1}^{d} \ln \left(h_{j t}\right)
$$


Where, $h_{j}$ indicates indicator j's poverty incidence (uncensored headcount ratio). This frequency weight assigns a higher weight to an indicator which has a lower deprived proportion. Unlike the other data-driven weighting structure, the frequency weighting structure has its own economic implications, it means, if a person is deprived in some indicator which is used universally now, this deprivation is considered very serious. Hence, for three dimensions: education, health, living standard, there are six different weighting structures which are: nested weights for each dimension with 10 indicators; nested weights for each dimension with 8 indicators; $50 \%, 25 \%, 25 \% ; 25 \%, 50 \%, 25 \% ; 25 \%, 25 \%, 50 \%$ and frequency weights, respectively. Subsequently we refer to these as weight0 to weight5, respectively.

\begin{tabular}{|l|l|l|l|l|l|}
\hline Weight0 & Weight1 & Weight2 & Weight3 & Weight4 & Weight5 \\
\hline 10-nested & 8 -nested & $50 \%$ education & $50 \%$ health & $\begin{array}{l}50 \% \text { living } \\
\text { standards }\end{array}$ & $\begin{array}{l}\text { Frequency } \\
\text { weights }\end{array}$ \\
\hline
\end{tabular}

First we calculate the Kendall $\tau$-b rank correlations of MPI with different weighting structure, and use the adjusted first-order stochastic dominance method to test the stability of MPI for the change of weighting.

\subsection{The correlation of MPI with different weighting structure}

Tables 5 and 6 provide the Kendall's $\tau$-b rank correlation coefficients ${ }^{10}$ among MPIs with different weights. The calculation is based on the pooled data. Although all the correlation coefficients are statistically significant at 5\% significant level, the scale of coefficients vary. As the correlation between MPI under weight1 and MPI under weight 3 is very large, the Kendall's rank correlation is 0.9271 . The next is correlation between MPI under weight 1 and MPI under weight 4 which is 0.8176 and 0.8451 , respectively. Correlation coefficients between each other MPI are lower, especially between weight 3 and weight 5 , is only 0.2075 . As we know, weight 1 is equal weight for each dimension, weight 3 and weight 4 are weight structure with lower weight for

10 The Spearman's rank correlation coefficients arrive at the same conclusions. 
education. Thus, all these indicate that the change of education's weight is important when we have the same indicators. In addition, the MPI is sensitive for the change from the normative weights to frequency weights.

Then, considering the change of indicators, we can find that the correlation between MPI under weight 0 and weight 2 is largest in column 1 in table 5 and table 6 , the following is weight5 and weight4.As we known from the previous content, we have two more indicators under weight0: Child mortality and floor material. While weight 3 endows more weight to health, so if the more weight to this dimension, the more change to the MPI if we change this dimension. Since the asset poverty is lower, the change of this dimension weight will have little effect, so the correlation between weight 4 and weight 0 is also a little higher. The weight5 is frequency weight, since its construction, the indicator poverty and indicator's weight restricted each other, thus it reduces effect of the change of indicators.

Table 6 lists out the Kendall's $\tau$-b rank correlation coefficients between MPIs with self-report health and MPI with BMI-for-age under different weights. Since the data of self-report health are only recorded from year 1997 to year 2006, so the calculation of correlation coefficients is also based on this time range in table 6. From the table 6, we can find that, first, although time horizon becomes shorter, from year 1997 to year 2006, the correlation among MPIs under different weights with the same indicator combinations are the same as before. Not only that, the strength of correlation relations between each measures are also very similar in each year, they don't change as the time goes by ${ }^{11}$. Second, the correlation among MPIs under different weights also does not change a lot for the substitution of health indicators. Third, the correlation coefficients among MPIs under different weights and different indictors drop sharply, especially when there is a large weight to the varied indicator, just as the weight 3 and weight 3 s showed in the table. All these illustrate that the MPI is stable on regional level, do not vary a lot as the time/datasets changes, but MPI is not stable on

\footnotetext{
${ }^{11}$ The correlation coefficients among each measures of each year are shown in the table A2 in this paper's appendix.
} 
individual level, when the weights or indicators have a variation, the outcomes identified by multidimensional method change a lot, especially for one varied indicator with a larger weight or varied weight of one indicator with larger poverty incidence.

Table 5 Kendall's $\tau$-b rank correlation coefficients for MPI with different weights

\begin{tabular}{lllllll}
\hline & Weight0 & Weight1 & Weight2 & Weight3 & Weight4 & Weight5 \\
\hline Weight0 & 0.9970 & & & & & \\
Weight1 & $0.5555^{*}$ & 1.0000 & & & & \\
Weight2 & $0.7140^{*}$ & $0.5947^{*}$ & 1.0000 & & & \\
Weight3 & $0.3859^{*}$ & $0.9271^{*}$ & $0.4877^{*}$ & 1.0000 & & \\
Weight4 & $0.6358^{*}$ & $0.8176^{*}$ & $0.6767^{*}$ & $0.7191^{*}$ & 1.0000 & \\
Weight5 & $0.6838^{*}$ & $0.3970^{*}$ & $0.5134^{*}$ & $0.2075^{*}$ & $0.5078^{*}$ & 1.0000 \\
\hline
\end{tabular}

Note:(1) * stands for statistically significant of the correlation coefficients at the 5\% level or lower. (2) weight0 refers to MPI under nested weight for each dimension with 10 indicators; weight1 refers to MPI under nested weight for each dimension with 8 indicators; weight2 refers to MPI with the weight structure 50\% 25\% 25\% for education, health and living standard; weight3 refers to MPI with the weight structure $25 \% 50 \% 25 \%$ for three dimensions; weight4 refers to MPI with the weight structure $25 \% 25 \% 50 \%$ for three dimensions and weight 5 refers to MPI under the frequency weight.

Table 6 Kendall's $\tau$-b rank correlation coefficients for different MPIs

\begin{tabular}{|c|c|c|c|c|c|c|c|c|c|}
\hline & Weight1 & Weight2 & Weight3 & Weight4 & Weight5 & Weight1s & Weight $2 \mathrm{~s}$ & Weight $3 \mathrm{~s}$ & Weight $4 \mathrm{~s}$ \\
\hline Weight1 & 1 & & & & & & & & \\
\hline Weight2 & $0.5806^{*}$ & 1 & & & & & & & \\
\hline Weight3 & $0.9443^{*}$ & $0.4876^{*}$ & 1 & & & & & & \\
\hline Weight4 & $0.8332 *$ & $0.6806^{*}$ & $0.7553^{*}$ & 1 & & & & & \\
\hline Weight5 & $0.3191 *$ & $0.4330^{*}$ & $0.1820^{*}$ & $0.3932^{*}$ & 1 & & & & \\
\hline Weight1s & $0.1770^{*}$ & $0.2217^{*}$ & $0.0867^{*}$ & $0.2091 *$ & $0.2558 *$ & 1.0000 & & & \\
\hline Weight $2 \mathrm{~s}$ & $0.1984 *$ & $0.5735^{*}$ & $0.0832 *$ & $0.2732 *$ & $0.3871^{*}$ & $0.5783^{*}$ & 1.0000 & & \\
\hline Weight $3 \mathrm{~s}$ & $0.0929 *$ & 0.1101* & $0.0749 *$ & $0.1061^{*}$ & $0.0816^{*}$ & $0.9388 *$ & $0.4762 *$ & 1.0000 & \\
\hline Weight 4 s & $0.2118^{*}$ & $0.3017 *$ & $0.1024 *$ & $0.3148^{*}$ & $0.3421 *$ & $0.8249 *$ & $0.6781 *$ & $0.7375 *$ & 1.0000 \\
\hline
\end{tabular}

Note: * stands for statistically significant of the correlation coefficients at $5 \%$ level or lower; Weigh0 to weight 5 have the same meaning as the table 5 . Weight $1 \mathrm{~s}$ to Weight $4 \mathrm{~s}$ refers to the MPI calculated with self-reported health under weight 1 to weight 4 ; The year range used for correlation calculation in this table is from 1997 to 2006. 


\subsection{First-order stochastic dominance (FOSD) analysis}

Our paper is also interested in the variation of multidimensional poverty status of specific individuals according to the different combinations of weights and dimensions. Hence, compared to the traditional FOSD method, we replace the horizontal axis with income cumulative proportion. The steps of constructions are as follows: First, sort the deprivation scores by the ascending income, and calculate the cumulative proportion of income, we can label it with $p$; Second, construct the cumulative function of individual deprivation scores by $p$, and define this function as $F(p)$.According to the construction of $\mathrm{M} 0, F(p)$ must satisfy: $p_{l}=F^{-1}\left(\sum_{i \leq l} \frac{\rho_{i}}{n M_{0}}\right)$. Then the definition of FOSD is as follows:

Given two different cumulative distribution functions $F_{1}(p)$ and $F_{2}(p), F_{1}(p)$ first-order stochastically dominates $F_{2}(p)$ if and only if $F_{1}(p)<F_{2}(p)$.

\section{Figure 8 The FOSD Analysis}

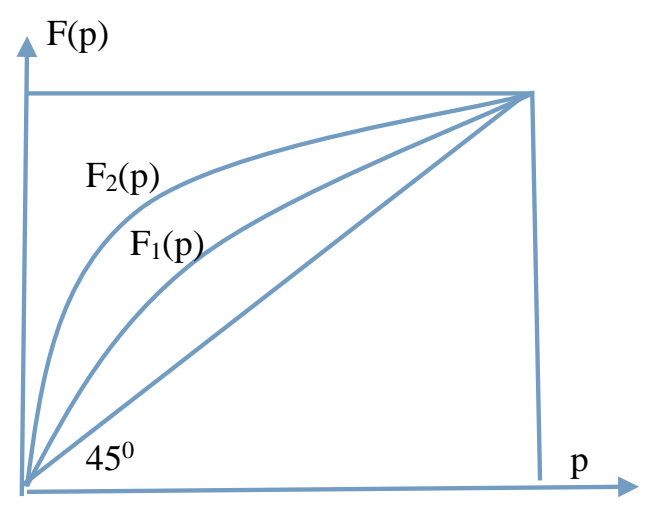

NOTE: $p$ is cumulative proportion of income in its ascending order $F(p)$ is cumulative proportion of multidimensional poverty.

The FOSD constructed here has three implications: First, if the distribution functions for two multidimensional poverty measures exist the relation of FOSD, then it means that there is significant difference between the outcomes identified by two different measures. Second, if two distribution functions exist the relation of FOSD, i.e. $F_{1}(p)$ 
and $F_{2}(p)$ with $F_{1}(p)<F_{2}(p)$ which is shown in figure 8 , then it can say that, under the situation of the second distribution, most of the multidimensional poor people are much more concentrated in the low-income group, which means its identified targets is more overlap with the income poor. Third, we could observe the difference of multidimensional poverty of different income groups. If the line coincide with the diagonal line, then it means the multidimensional poverty uniformly lays among different income groups and there is no difference in multidimensional poverty among different income groups.

As the figure 9 shows, there are three levels of dominance relations among China's multidimensional poverty measures with different weights: MPI under frequency weight; MPI under weight2 and weight4; MPI under weight1 and weight 3 . And the dominance relations are as follows: the MPI under frequency weight dominates the MPI under weight 2 and weight 4 , and the MPI under weight 2 and weight 4 dominates the MPI under weight 1 and weight3. First, the MPI under frequency weight dominates all other multidimensional poverty measures in all the years. This means that, on the one hand, multidimensional poverty measures under frequency weight has a great difference from the measures under normative weights, and this conclusion is similar to the conclusions from the correlation analysis. On the other hand, compared to the other measures, the poverty under frequency weights is more concentrated towards the lower income group, especially after year 2004.

Second, among the measures under normative weights, the measures under weight 4 and weight 2 dominate measures under weight 1 and weight 3 , and the meaning of dominance is the same with the frequency weight as before. The weight 2 and weight 4 endow more weight to education and standard living, respectively. The reason of dominance may be that these two dimensions are highly related to the income. In fact, the MPI under equal weight structure dominates the MPI under weight3 which endows more weight to health, but this dominance relation becomes not significant as time goes on. As the figure A3 to figure A7 in the appendix shows, when we substitute BMI-for-age with self-report health, the dominance relations between each MPI with 
different weight structures totally don't change at all. And the dominance relation between MPI with this two types of health indicators under the same weight structures are not obvious.

Hence, weighting structure plays an important role in multidimensional poverty measurement. The change of weights affects the distribution of multidimensional poverty. But if we control the weights, the substitution of indicators does not have a significant effect on the dominance relations among different multidimensional measures

Figure 9 FOSD analysis among different MPIs 1989-2011

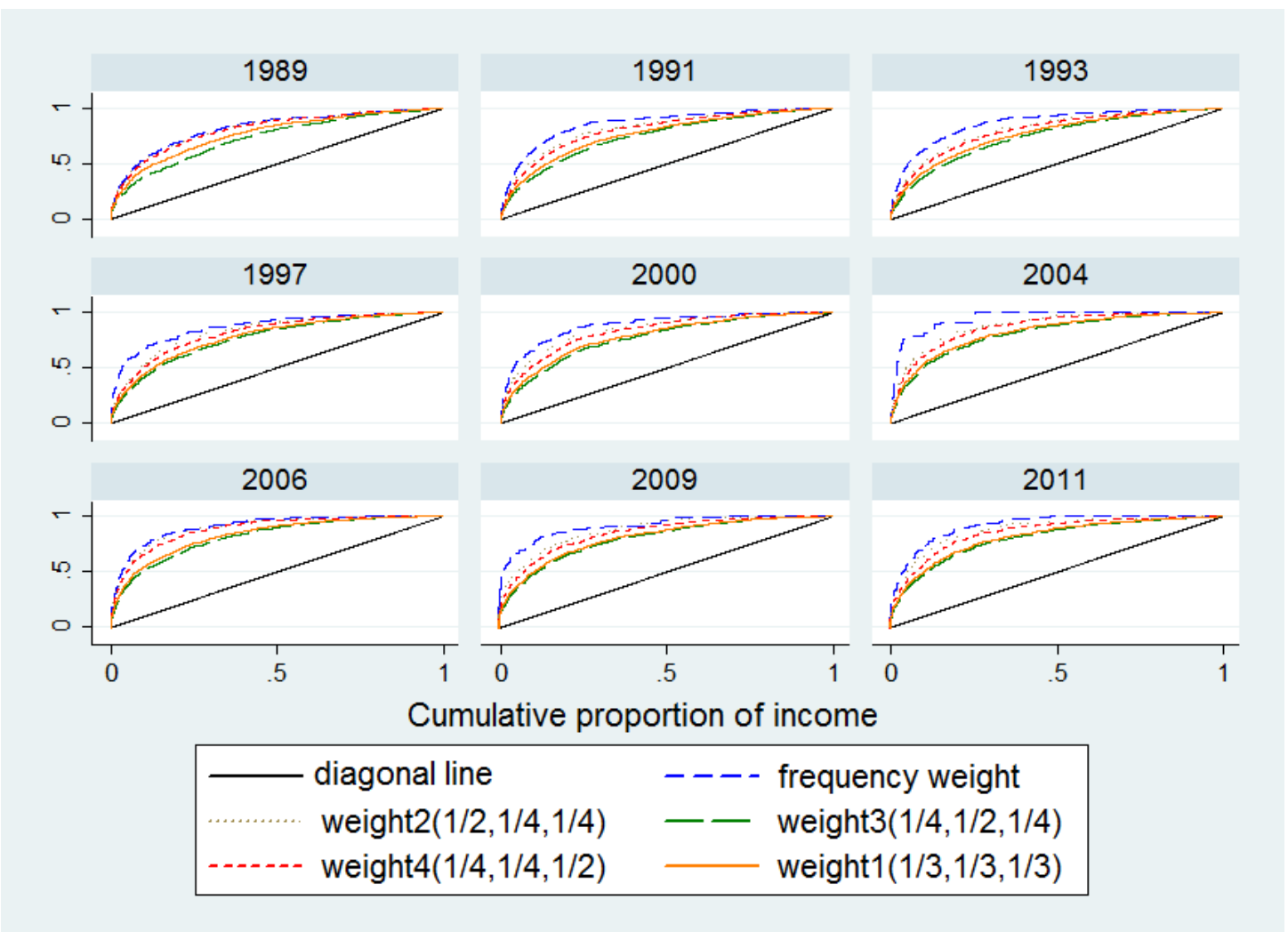

Note: weight1 refers to MPI under equal weight for each dimension with 8 indicators; weight2 refers to MPI with the weight structure $50 \% 25 \% 25 \%$ for education, health and living standard; weight3 refers to MPI with the weight structure $25 \% 50 \% 25 \%$ for three dimensions; weight4 refers to MPI with the weight structure $25 \% 25 \% 50 \%$ for three dimensions and weight5 refers to MPI under the frequency weight. 


\section{Multidimensional poverty vs. income poverty}

Because of different features between income and the indicators in the multidimensional measures, income poverty may have a great difference from the multidimensional poverty. In a certain sense, income poverty can be used to reflect the contemporaneous poverty status, and multidimensional measures may give a report on persistent poverty and poverty vulnerability. In this part, we will take a description and regression analysis on the differences among each poverty measures.

\subsection{The difference between multidimensional poverty and income poverty}

As the table 7 shows that, there is a great difference between multidimensional poverty measurement and income poverty measurement. The proportion of people who are identified as both multidimensional poor and income poor is very low and also declines over time. In 2011, although the headcount ratio of multidimensional poverty and income poverty are $11.36 \%$ and $10.42 \%$, respectively,there is only $1.96 \%$ households who are both multidimensional poor and income poor. In year 1989, there are 10.32 percent people are both multidimensional poor and income poor, and in year 2011, there are only 1.96 percent. There is an obviously decline in this proportion from year 1989 to year 2011.There are two reasons: First, it is because both the multidimensional poor population and income poor population decline very quickly over the time. Second, it indicates that the difference becomes larger for the identified poor objects between multidimensional measures and income measures. In fact, the proportion of households who are multidimensional poor but not income poor is very stable, and maintains around $11 \%$. This stability suggests that the most of reduction of multidimensional poverty may be due to the reduction of income poverty. If we aim to reduce the multidimensional poverty, then the policy must turn to the improvement of people's capability.

In the table 8 , we find that the extremely permanent multidimensional poverty is more severe than income poverty, 19 households are multidimensional poverty in all 9 round surveys for 22 years long, but there are only 4 households are income poverty in all 9 
round surveys. These long-lasting household between two measures are totally different each other, for these 4 households with 22 years long in income poor, where 2 households have never been multidimensional poor, and other 2 households just have been in multidimensional poor for once. However, since the proportion of household who has ever been poor in 9 round surveys is higher than multidimensional poverty measures, it seems that the income poverty has a higher mobility. In this paper, the long-lasting poverty also means that the household exits intergenerational poverty, because with the efforts of many generations, all the household members have failed to improve on their education, health and living standard. Since the attributes between the multidimensional poverty and income poverty are different, it is necessary for us to further analyze the dynamic change of each dimension for this household to understand why the household traps into intergenerational multidimensional poverty.

The differences between income poverty and multidimensional poverty with panel data are shown in the table $7 \mathrm{a}$ and Table $8 \mathrm{a}$. The outcome shows that they are similar to the longitudinal data in table 7 and table 8. Although the headcount ratio of multidimensional poverty and income poverty are as high as $17.31 \%$ and $15.29 \%$ in 2011, respectively, there is only $2.34 \%$ households who are both multidimensional poor and income poor.

Table 7 The distribution of poor people for multidimensional (MD) and income (\%)

\begin{tabular}{lccccccccc}
\hline & 1989 & 1991 & 1993 & 1997 & 2000 & 2004 & 2006 & 2009 & 2011 \\
\hline $\begin{array}{l}\text { Both not MD poor } \\
\text { and income poor }\end{array}$ & 47.94 & 42.61 & 44.67 & 56.64 & 61.89 & 67.09 & 68.20 & 75.06 & 76.26 \\
$\begin{array}{l}\text { MD poor, } \\
\text { not income poor }\end{array}$ & 9.53 & 13.09 & 12.86 & 12.13 & 12.25 & 10.40 & 10.37 & 12.60 & 11.36 \\
$\begin{array}{l}\text { Income poor, } \\
\text { not MD poor }\end{array}$ & 32.21 & 27.99 & 29.11 & 22.74 & 20.05 & 17.79 & 17.17 & 9.89 & 10.42 \\
$\begin{array}{l}\text { Both MD poor and } \\
\text { income poor }\end{array}$ & 10.32 & 16.31 & 13.36 & 8.49 & 5.81 & 4.74 & 4.26 & 2.44 & 1.96 \\
\hline
\end{tabular}


Table 7a The distribution of poor people for MD and income with panel data

(\%)

\begin{tabular}{lccccccccc}
\hline & 1989 & 1991 & 1993 & 1997 & 2000 & 2004 & 2006 & 2009 & 2011 \\
\hline MD poor & 23.03 & 33.31 & 28.17 & 23.36 & 20.62 & 18.22 & 17.96 & 17.96 & 17.31 \\
$\begin{array}{l}\text { Income poor } \\
\text { Both not MD poor }\end{array}$ & 31.53 & 54.78 & 50.29 & 36.96 & 31.36 & 26.74 & 25.76 & 14.12 & 15.29 \\
$\begin{array}{l}\text { and income poor } \\
\text { MD poor, not }\end{array}$ & 9.24 & 12.1 & 12.3 & 13.01 & 13.14 & 11.58 & 12.17 & 15.16 & 14.96 \\
$\begin{array}{l}\text { income poor } \\
\begin{array}{l}\text { Income poor, not } \\
\text { MD poor }\end{array}\end{array}$ & 37.74 & 33.57 & 34.42 & 26.61 & 23.88 & 20.1 & 19.97 & 11.32 & 12.95 \\
$\begin{array}{l}\text { Both MD poor and } \\
\text { income poor }\end{array}$ & 13.79 & 21.21 & 15.88 & 10.34 & 7.48 & 6.64 & 5.79 & 2.8 & 2.34 \\
\hline
\end{tabular}

Note: The sample size for panel data is 1537 households each year.

Table 8 The number of income poverty and multidimensional poverty waves

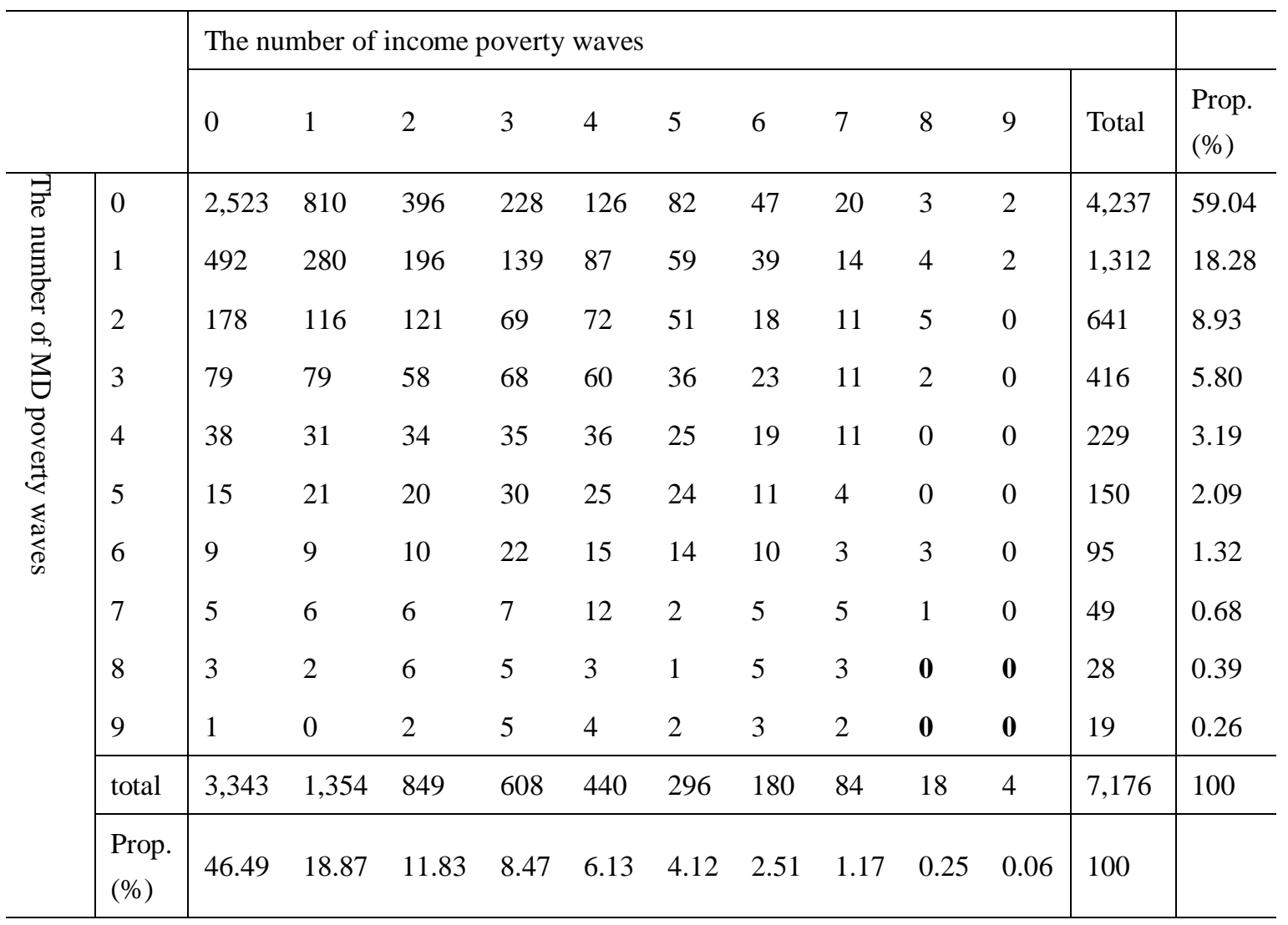


Table 8a The number of income poverty and MD poverty waves with panel data

\begin{tabular}{|c|c|c|c|c|c|c|c|c|c|c|c|c|}
\hline \multirow{12}{*}{ 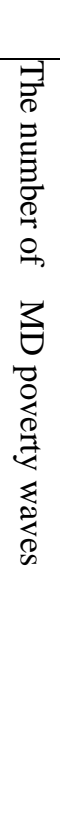 } & \multicolumn{11}{|c|}{ The number of income poverty waves } & \multirow[b]{2}{*}{ Total } \\
\hline & & 0 & 1 & 2 & 3 & 4 & 5 & 6 & 7 & 8 & 9 & \\
\hline & 0 & 95 & 78 & 89 & 75 & 61 & 43 & 31 & 14 & 3 & 2 & 491 \\
\hline & 1 & 34 & 51 & 58 & 61 & 43 & 34 & 30 & 12 & 3 & 2 & 328 \\
\hline & 2 & 23 & 26 & 39 & 34 & 37 & 35 & 14 & 11 & 4 & 0 & 223 \\
\hline & 3 & 23 & 13 & 19 & 40 & 29 & 24 & 17 & 9 & 2 & 0 & 176 \\
\hline & 4 & 7 & 9 & 14 & 16 & 20 & 18 & 11 & 7 & 0 & 0 & 102 \\
\hline & 5 & 4 & 7 & 7 & 18 & 14 & 20 & 8 & 1 & 0 & 0 & 79 \\
\hline & 6 & 3 & 7 & 8 & 16 & 9 & 6 & 5 & 3 & 2 & 0 & 59 \\
\hline & 7 & 4 & 4 & 4 & 6 & 9 & 2 & 4 & 3 & 1 & 0 & 37 \\
\hline & 8 & 3 & 1 & 6 & 4 & 2 & 1 & 4 & 2 & $\mathbf{0}$ & 0 & 23 \\
\hline & 9 & 1 & 0 & 2 & 5 & 4 & 2 & 3 & 2 & $\mathbf{0}$ & 0 & 19 \\
\hline & Total & 197 & 196 & 246 & 275 & 228 & 185 & 127 & 64 & 15 & 4 & 1,537 \\
\hline
\end{tabular}

Note: The sample size for panel data is 1537 households each year.

\subsection{Regression analysis}

In the following part of the paper, we use the panel logit model to analyze where the difference between income poverty and multidimensional poverty comes from. We compare multidimensional poverty of different weight structures with the income poverty. The explained variables are mainly characteristics of the household and the head of household. Since most of the explained variables are time-invariant, including the control of the gender, provinces and urban-rural division, in order to keep estimation efficiency, we fits with the random effects logit model. As the table 9 shows, the regression outcomes among different measures are not very consistent each other.

First, for the age of household head, all the poverty measures have the same trend and all are statistically significant: the poverty decreases as the age increases, when the age grows over some point, the poverty begins to increase as the age increases. But the turn points are not the same between multidimensional measures and income measures, they are around 55 years old for all multidimensional measures, and is 
about 70 years old for income measures. This outcome consists with the nature of indicators we have chosen. It indicates that the multidimensional poverty is shaped very early, and it would be persistent and hard to be eliminated for policies.

Compared with the male-headed households, the female-headed households have a lower probability of being poor for all poverty measures, and the outcomes are all significant, especially for those married-female-headed households. But for those divorced- or widowed-female-headed households, they will have a higher possibility to be poor. It is necessary for us to analyze the household structure to learn about the reason of this phenomenon in later research. But according to our conclusions, it is not suitable for targeting female-headed households to reduce poverty, which is similar to Oginni et al (2013), Montoya and Teixeira(2017).For marital status, relative to households whose head are unmarried, the households with married head have a lower possibility to be poor for all the measures. Divorced or separated families have a higher probability of being poor for income poverty measures, but have a lower possibility to be poor for multidimensional poverty measures, and it's similar for the widowed. It seems outcomes of income measures conform to our common sense. The conclusions from multidimensional poverty may be due to nature of the indicators which we previous discussed.

As expected, the effect of education is significantly positive to reduce multidimensional poverty and income poverty, the households whose heads have a higher education will have a lower possibility to be poor. And national minority families have a higher probability of being poor relative to the families who are the Han nationality.

For the work type, relative to no job, the households whose heads have jobs will have a significantly lower possibility to be income poor, no matter what's type of his occupation. But more skilled or senior the head's occupation is, much lower possibility to be income poor the household is. Among all the types of occupation, farmer or hunter headed households have a higher possibility to be income poor. However, the effects of occupation on multidimensional poverty measures are 
different from the income poverty measures. Relative to no job, the households whose heads are farmer/hunter will have a significantly higher possibility to be multidimensional poor, while other types of the occupation have no significant effect on multidimensional poor, the senior or skilled worker even have a higher probability of being poor. For the farmer/hunter, it's easy to understand why, because in multidimensional poverty measures, the people lived in rural areas (most of them are farmers or lower skilled workers) are seriously deprived in three indicators: sanitation facility, cooking fuel and drinking water, while these three indicators have a very high poverty incidence according to the table 2 . What's more, according to the regression analysis of different measures, we find that, the people who live in rural area have a higher possibility to be poor for all types of measures.

For household size, the probability of being poor is monotonically increasing for income poverty and multidimensional poverty under weight1, weight 3 and weight 4 , and is monotonically decreasing for multidimensional poverty under frequency weight and weight 2 which endows $50 \%$ weight to education, so it indicates that education poverty decreases as the household size increases.

For the different provinces, basically, developed provinces have a lower poverty incidence, but there is not a regular mode for all the measures. Compared to the reference province-Liaoning province, people lived in Shandong province have the lowest probability of being multidimensional poor, except for the outcome under frequency weight, but have a higher possibility to be income poor. On the contrary, people lived in Jiangsu province have the lowest possibility to be income poor, but have a higher possibility to be multidimensional poor. As a whole, the distribution of income poverty is not totally same with the multidimensional poverty.

As the regression analysis shows, compared to income poverty, all multidimensional poverty measures possess some common characteristics, but there are also some differences among each multidimensional measures which will be a big challenge to policy makers to make sure which type of multidimensional poverty measures is more reasonable. Of course, it should be prudent to explain the regression outcomes which 
just aim at our specific choice of weights and indicators in this paper. If we control the household income in regression analysis on multidimensional poverty ${ }^{12}$, the estimation outcomes only have subtle changes, but all the effects reduce a little. It indicates that these household characteristics have some indirect effects through income to the multidimensional poverty.

Table 9 Panel logit regression under different multidimensional poverty measures

\begin{tabular}{|c|c|c|c|c|c|c|}
\hline \multirow[b]{3}{*}{ VARIABLES } & (1) & (2) & (3) & (4) & (5) & (6) \\
\hline & \multicolumn{5}{|c|}{ Multidimensional poverty } & \multirow{2}{*}{$\begin{array}{l}\text { Income } \\
\text { poverty }\end{array}$} \\
\hline & Weight1 & Weight5 & Weight2 & Weight3 & Weight4 & \\
\hline \multirow[t]{2}{*}{ Age } & $-0.124 * * *$ & $-0.235 * * *$ & $-0.208 * * *$ & $-0.113 * * *$ & $-0.176 * * *$ & $-0.164 * * *$ \\
\hline & $(0.00986)$ & $(0.0163)$ & $(0.0118)$ & $(0.0103)$ & $(0.0108)$ & $(0.00790)$ \\
\hline \multirow[t]{2}{*}{ Age squared } & $0.00116^{* * *}$ & $0.00190 * * *$ & $0.00190 * * *$ & $0.00109 * * *$ & $0.00154 * * *$ & $0.00117 * * *$ \\
\hline & $(9.51 \mathrm{e}-05)$ & $(0.000155)$ & $(0.000112)$ & $(9.98 \mathrm{e}-05)$ & $(0.000104)$ & $(7.55 \mathrm{e}-05)$ \\
\hline \multirow[t]{2}{*}{ Female } & $-0.151^{*}$ & $-0.454 * * *$ & $-0.435^{* * *}$ & -0.125 & $-0.339 * * *$ & $-0.300 * * *$ \\
\hline & $(0.0831)$ & $(0.143)$ & $(0.102)$ & $(0.0866)$ & $(0.0951)$ & $(0.0614)$ \\
\hline \multirow[t]{2}{*}{ Married } & -0.0532 & $-0.577 * * *$ & $-0.401 * *$ & 0.0813 & -0.145 & -0.111 \\
\hline & $(0.154)$ & $(0.219)$ & $(0.175)$ & $(0.166)$ & (0.164) & $(0.124)$ \\
\hline \multirow[t]{2}{*}{ Divorced/separated } & 0.118 & -0.425 & $-0.817 * * *$ & 0.281 & $-0.554 * *$ & $0.354 *$ \\
\hline & $(0.230)$ & $(0.387)$ & $(0.300)$ & $(0.245)$ & $(0.282)$ & $(0.185)$ \\
\hline \multirow[t]{2}{*}{ Widowed } & 0.148 & $-0.437 *$ & -0.118 & 0.255 & 0.0616 & $0.244^{*}$ \\
\hline & $(0.173)$ & $(0.252)$ & $(0.196)$ & $(0.186)$ & $(0.186)$ & $(0.138)$ \\
\hline \multirow[t]{2}{*}{ Ethnic Minority } & 0.0595 & $0.376 * * *$ & $0.197 * *$ & 0.0531 & $0.345^{* * *}$ & $0.247 * * *$ \\
\hline & $(0.0860)$ & $(0.137)$ & $(0.0995)$ & $(0.0889)$ & $(0.0925)$ & $(0.0626)$ \\
\hline \multirow[t]{2}{*}{ Primary school } & $-0.463 * * *$ & $-1.937 * * *$ & $-1.853 * * *$ & -0.0297 & $-0.788 * * *$ & $-0.613 * * *$ \\
\hline & $(0.0653)$ & $(0.114)$ & $(0.0777)$ & $(0.0687)$ & $(0.0700)$ & $(0.0500)$ \\
\hline \multirow[t]{2}{*}{ Lower middle school } & $-0.639 * * *$ & $-2.531 * * *$ & $-2.382 * * *$ & $-0.122 *$ & $-1.286^{* * *}$ & $-1.161 * * *$ \\
\hline & $(0.0708)$ & $(0.132)$ & $(0.0891)$ & $(0.0741)$ & $(0.0784)$ & $(0.0548)$ \\
\hline \multirow[t]{2}{*}{ Upper middle school } & $-0.686^{* * * *}$ & $-2.636 * * *$ & $-2.430 * * *$ & $-0.167 *$ & $-1.372 * * *$ & $-1.353 * * *$ \\
\hline & $(0.0940)$ & $(0.195)$ & $(0.130)$ & $(0.0971)$ & $(0.110)$ & $(0.0732)$ \\
\hline \multirow{2}{*}{$\begin{array}{c}\text { Technical/Vocational } \\
\text { school }\end{array}$} & $-0.868 * * *$ & $-3.654 * * *$ & $-3.232 * * *$ & $-0.389 * * *$ & $-1.820 * * *$ & $-2.031 * * *$ \\
\hline & $(0.141)$ & $(0.639)$ & $(0.309)$ & $(0.144)$ & $(0.203)$ & $(0.135)$ \\
\hline
\end{tabular}

${ }^{12}$ The regression outcomes with household income controlled are not shown in this paper. 


\begin{tabular}{|c|c|c|c|c|c|c|}
\hline \multirow[t]{2}{*}{ University/college } & $-0.877 * * *$ & -21.61 & $-4.001 * * *$ & $-0.402 * * *$ & $-2.132 * * *$ & $-3.069 * * *$ \\
\hline & $(0.150)$ & $(5,356)$ & $(0.477)$ & $(0.153)$ & $(0.252)$ & $(0.210)$ \\
\hline Professional/technical/ & $0.202 * * *$ & -0.104 & -0.0754 & $0.187^{* *}$ & $0.162 *$ & $-1.195 * * *$ \\
\hline skilled worker & $(0.0765)$ & $(0.199)$ & $(0.120)$ & $(0.0786)$ & $(0.0975)$ & $(0.0675)$ \\
\hline \multirow[t]{2}{*}{ Non-skilled worker } & 0.0797 & -0.0130 & 0.0986 & 0.0930 & $0.286 * * *$ & $-0.969 * * *$ \\
\hline & $(0.0907)$ & $(0.196)$ & $(0.123)$ & $(0.0935)$ & $(0.106)$ & $(0.0765)$ \\
\hline \multirow[t]{2}{*}{ Service workers } & 0.114 & 0.133 & 0.0826 & 0.0611 & 0.148 & $-1.065^{* * *}$ \\
\hline & $(0.0890)$ & $(0.203)$ & $(0.128)$ & $(0.0918)$ & $(0.109)$ & $(0.0773)$ \\
\hline \multirow[t]{2}{*}{ Farmer } & $0.389 * * *$ & $1.128 * * *$ & $0.866 * * *$ & $0.292 * * *$ & $0.833 * * *$ & $0.258 * * *$ \\
\hline & $(0.0643)$ & $(0.120)$ & $(0.0778)$ & $(0.0677)$ & $(0.0722)$ & $(0.0507)$ \\
\hline \multirow[t]{2}{*}{ Household size } & $0.261 * * *$ & $-0.0842 * * *$ & $-0.0705 * * *$ & $0.342 * * *$ & $0.181 * * *$ & $0.240 * * *$ \\
\hline & $(0.0148)$ & $(0.0253)$ & $(0.0174)$ & $(0.0156)$ & $(0.0159)$ & $(0.0120)$ \\
\hline \multirow[t]{2}{*}{ Urban } & $-0.289 * * *$ & $-1.682 * * *$ & $-1.980 * * *$ & -0.0590 & $-1.220 * * *$ & 0.00280 \\
\hline & $(0.0669)$ & $(0.155)$ & $(0.101)$ & $(0.0689)$ & $(0.0824)$ & $(0.0499)$ \\
\hline \multirow[t]{2}{*}{ Heilongjiang } & 0.0565 & -0.266 & 0.0502 & -0.00766 & 0.228 & -0.0537 \\
\hline & $(0.137)$ & $(0.284)$ & $(0.166)$ & $(0.142)$ & $(0.156)$ & $(0.0996)$ \\
\hline \multirow[t]{2}{*}{ Jiangsu } & $0.355^{* * *}$ & $1.481 * * *$ & 0.130 & $0.266^{* *}$ & $0.314 * *$ & $-0.344 * * *$ \\
\hline & $(0.125)$ & $(0.233)$ & $(0.156)$ & $(0.129)$ & $(0.146)$ & $(0.0957)$ \\
\hline \multirow[t]{2}{*}{ Shandong } & $-0.573 * * *$ & $0.669 * * *$ & -0.124 & $-0.733 * * *$ & -0.133 & $0.324 * * *$ \\
\hline & $(0.133)$ & $(0.245)$ & $(0.156)$ & $(0.140)$ & $(0.150)$ & $(0.0904)$ \\
\hline \multirow[t]{2}{*}{ Henan } & -0.0558 & $1.370 * * *$ & -0.0768 & $-0.241 *$ & $0.455^{* * *}$ & $0.846^{* * *} *$ \\
\hline & $(0.126)$ & $(0.228)$ & $(0.153)$ & $(0.132)$ & $(0.141)$ & $(0.0882)$ \\
\hline \multirow[t]{2}{*}{ Hubei } & $0.556^{* * *}$ & $1.306^{* * *}$ & $0.662 * * *$ & $0.476 * * *$ & $0.954 * * *$ & $0.421 * * *$ \\
\hline & $(0.125)$ & $(0.231)$ & $(0.149)$ & $(0.129)$ & $(0.140)$ & $(0.0902)$ \\
\hline \multirow[t]{2}{*}{ Hunan } & $0.507 * * *$ & 0.143 & -0.0977 & $0.559 * * *$ & $0.532 * * *$ & $0.313^{* * *}$ \\
\hline & $(0.123)$ & $(0.249)$ & $(0.155)$ & $(0.126)$ & $(0.141)$ & $(0.0895)$ \\
\hline \multirow[t]{2}{*}{ Guangxi } & $1.300 * * *$ & $1.578 * * *$ & $1.139 * * *$ & $1.290 * * *$ & $1.316^{* * *}$ & $0.272 * * *$ \\
\hline & $(0.119)$ & $(0.227)$ & $(0.143)$ & $(0.123)$ & $(0.136)$ & $(0.0885)$ \\
\hline \multirow[t]{2}{*}{ Guizhou } & $1.019 * * *$ & $1.260 * * *$ & $0.867 * * *$ & $0.956 * * *$ & $1.168 * * *$ & $0.327 * * *$ \\
\hline & $(0.120)$ & $(0.223)$ & $(0.144)$ & $(0.124)$ & $(0.136)$ & $(0.0887)$ \\
\hline \multirow[t]{2}{*}{ Constant } & -0.0862 & $3.404 * * *$ & $4.200 * * *$ & $-1.415^{* * *}$ & $1.572 * * *$ & $3.738 * * *$ \\
\hline & $(0.301)$ & $(0.477)$ & $(0.354)$ & $(0.316)$ & $(0.324)$ & $(0.242)$ \\
\hline Observations & 34,496 & 34,496 & 34,496 & 34,496 & 34,496 & 34,496 \\
\hline
\end{tabular}

Notes: (1) Standard errors in parentheses; $* * * \mathrm{p}<0.01, * * \mathrm{p}<0.05, * \mathrm{p}<0.1$. (2) weight1 refers to equal weight for each dimension, weight 2 refers to weight structure with $50 \%, 25 \%, 25 \%$ for education, health and living standard, weight 3 refers to weight structure with $25 \% 50 \% 25 \%$ for three dimensions, 
weight4 refers to weight structure with $25 \%, 25 \%, 50 \%$ for three dimensions and weight5 refers to the frequency weight. (3) Ethnic minority, gender, age, marital status, education, work type are characteristics of head of household; household size are household variables; Urban and province are regional variables. (4) Marital status of the household head has five types, including never married; married; divorced/separated; widowed, and never married is the reference. Education level of the household head attained has 6 categories: no school completely or not graduated from the primary school; graduated from primary school; lower middle school degree; upper middle school degree; technical or vocational degree; university or college degree or higher; and the first one is the reference. Work type has 6 categories: no job; professional / technical worker / administrator / executive / manager / office staff / skilled worker; non-skilled worker; army officer / police officer / soldier / policeman / driver / service worker / athlete / actor; farmer / fisherman / hunter; the reference is type of no job. For the province, Liaoning is the reference.

\section{Discussions and conclusions}

As all discussed above, poverty is multidimensional. And then, in the perspective of multidimensional, it has to choose three ingredients: indicators, weight structure, aggregation procedures. However, there is no theory and an authoritative consensus of opinion to make sure that there is a reasonable choice for these ingredients. If so, it's very harmful for multidimensional poverty measures to be used for policy making. Based on the structure of global MPI, our paper chooses three dimensions, including education, health and living standard, to dynamically measure China's multidimensional poverty, and use the FOSD and regression analysis to compare different multidimensional poverty measures with income poverty measures.

First, both the income poverty and multidimensional poverty decline quickly as the time goes, and rural multidimensional poverty is more severe than urban areas, especially in sanitation, drinking water and cooking fuel, it mainly attributes to the segregation produced by the China's registration system and its induced formed rural living habits, lagged infrastructure construction and high transformation costs. In addition, in recent years, rural education even deteriorates and rural malnutrition is still not very optimistic. These conclusions just underline the importance of indicator's choice. What about the people living in urban areas? In China's urban areas, people may be deprived in clean environment, accommodation, employment and so on. As independent setup of urban poverty line for income poverty 
measurements, it may need to build another indicator system for multidimensional poverty measurements.

Second, since the attributes of income and indicators in multidimensional poverty are different, we find that, compared to the income poverty, the multidimensional poverty declines gently over the time, and it is much more persistent. For the major regional characteristics, poverty under multidimensional measures do not have a great difference from the income measures, the poverty in urban areas or in the east developed provinces are much lower, it means that the variation of weight does not change the rank on regional level very much. However, if considering some specific household characteristics, we find that, multidimensional poverty under different weights and income poverty have a great difference from each other, but if controlling weights, the substitution of indicators does not change the dominance relation among each multidimensional poverty measures under different weights.

China aims to completely eradicate the rural extreme poverty by 2020 , and stresses targeted measures to lift more people out of poverty which put forward by President $\mathrm{Xi}$ Jinping. Because of advantages of multidimensional poverty measures on revealing the nature of poverty, efficiency of poverty information transmission, targeting policy making, and so on, multidimensional poverty measures will play an important role in the next stage of China's poverty reduction. 


\section{References:}

[1] Alkire, S., The Missing Dimensions of Poverty Data: Introduction to the Special Issue, Oxford Development Studies, 2007, Vol. 35(4): 347-359.

[2] Alkire, S., Choosing Dimensions: The Capability Approach and Multidimensional Poverty, MPRA Working paper No. 8862, 2008.

[3] Alkire, S. and J. Foster, Counting and Multidimensional Poverty Measurement, OPHI Working paper, 2007.

[4] Alkire, S. and J. Foster, Counting and Multidimensional Poverty Measurement, Journal of Public Economics, 2011, Vol. 95(7-8): 476-487.

[5] Alkire, S., J. Foster, S. Seth, J.M. Roche and P. Ballon, Multidimensional Poverty Measurement and Analysis, Oxford: Oxford University Press, 2015.

[6] Alkire, S., Jindra, C., Robles, G. and Vaz, A. (2016). "Multidimensional Poverty Index - 2016: Brief methodological note and results." OPHI Briefing 42, University of Oxford.

[7] Alkire, S. and S. Seth, Multidimensional poverty reduction in India between 1999 and 2006: Where and How? World Development, 2015, Vol. 72: 93-108.

[8] Alkire, S. and M. E. Santos, Measuring Acute Poverty in the Developing World: Robustness and Scope of the Multidimensional Poverty Index, World Development, 2014, Vol. 59: 251-274.

[9] Anand, S. and Sen, A. Concepts of Human Development and Poverty: A Multidimensional Perspective, In United Nations Development Programme, Poverty and human development: Human development papers 1997.New York: United Nations, 1997, pp. 1-20.

[10]Arrow, K. J., A difficulty in the Concept of Social Welfare, Journal of Political Economy,1950, Vol. 58(4): 328-346.

[11]Banerjee, A. V. and E. Duflo, Poor Economics: A Radical Rethinking of the Way to Fight Global Poverty, U.S.: Public Affairs, 2011. 
[12]Bourguignon, F. and Satya R. Chakravarty, The measurement of multidimensional poverty, Journal of Economic Inequality, 2003, Vol. 1(1): 25-49.

[13]Cohen, G. A. Equality of what? On welfare, goods, and capabilities, In Nussbaum, M. and A. Sen (ed.), The Quality of Life, Oxford: Clarendon Press.1993, p. 9-29.

[14]Davidson, R. and J-Y. Duclos, Statistical Inference for Stochastic Dominance and for the Measurement of Poverty and Inequality, Econometrica, 2000, Vol. 68(6): $1435-1464$.

[15]Decancq, K. and M. A. Lugo, Weights in Multidimensional Indices of Wellbeing: An overview, Econometric Reviews, 2013, Vol. 32(1): 7-34.

[16]Deutsch, J. and J. Silber, Measuring multidimensional poverty: An empirical comparison of various approaches, Review of Income and Wealth, 2005, Vol. 51(1): 145-174.

[17]Duclos, J-Y, P. Makdissi, Squential Stochastic Dominance and the Robustness of Poverty Orderings, Review of Income and Wealth, 2005, Vol. 51(1): 63-87.

[18]Duclos, J-Y, D. Sahn and S. D. Younger, Robust Multidimensional Poverty Comparisons, The Economic Journal, 2006, Vol. 116(514): 943-968.

[19]Duflo, E., M. Greenstone, R. Guiteras and T. Clasen, Toilets can Work: Short and Medium Run Health Impacts of Addressing Complementaries and Externalities in Water and Sanitation, Working Paper, 2015.

[20]Foster. J, Greer. J and Thorbecke, E., A class of decomposable poverty measures, Econometrica, 1984, Vol. 52(3): 761-766.

[21]Foster, J. E., M. McGillivray and S. Seth, Rank Robustness of Composite Indices, Econometric Reviews, 2013,32(1): 33-56.

[22]Hume, D. A Treatise of Human Nature, In: D. F. Norton and M. J. Norton (eds.) A Treatise of Human Nature, Oxford: Oxford University Press, 2000 (1739-1740).

[23]Labar, K. and Bresson, F., A multidimensional analysis of poverty in China from 1991 to 2006. China Economic Review, 2011, 22(3): 646-668. 
[24] Khan, A. U., A. Saboor, A. Hussain, S. Sadiq and A. Q. Mohsin, Investigating Multidimensional Poverty across regions in Sindh province of Pakistan,Social Indicators Research, 2013, 119(1): 515-532.

[25]Montoya, A. and K. Teixeria, Multidimensional Poverty in Nicargua: Are Female Headed Households Better Off? Social Indicators Research, 2017, 132: 1037-1063.

[26]Njong, M.A. and P. Ningaye, Characterizing weights in the measurement of multidimensional poverty: An application of data-driven approaches to Cameroonian data, OPHI Working Paper No. 21, 2008.

[27] Oginni, A., B. Ahonsi and F. Ukwuije, Are female-headed households typically poorer than male-headed households in Nigeria, The Journal of Socio-Economics, 2013, 45: 132-137.

[28]Putnam, H., The Collapse of the Fact/Value Dichotomy and other Essays, Harvard University Press, 2004.

[29]Sen, A. K. The Nature and Classes of Prescriptive Judgements, The Philosophical Quarterly, 1967, Vol. 17(66): 46-62.

[30]Sen, A. K., Poverty: An Ordinal Approach to Measurement, Econometrica, 1976, Vol. 44(2): 219-231.

[31]Sen, A. K., Commodities and Capabilities, Amsterdam: North Holland, 1985.

[32]Sen, A. K., Development as freedom. Oxford: Oxford University Press, 1999.

[33]Tsui, K. Y., Multidimensional poverty index, Social Choice and Welfare, 2002, Vol. 19 (1): 69-93.

[34]UN, 2003, Indicators for monitoring the Millennium Development Goals. New York: United Nations.

[35]UNESCO, 2010, Reaching the marginalized, Oxford: Oxford University Press.

[36]Wang, X. L. and S. Alkire, Measurement of Multidimensional Poverty in China: 
Estimation and Policy Implications, Chinese Rural Economy (in Chinese), 2009, 12: 4-23.

[37]Wang, X., Feng, H., Xia, Q. and Alkire, S., On the relationship between income poverty and multidimensional poverty in China. OPHI Working Paper, 101, University of Oxford.

[38] Yu. J., Multidimensional poverty in China: Findings based on the CHNS. Social Indicators Research, 2013, 112(2): 315-336

[39]Zou, W. and Y. F. Fang, A multidimensional study of China's Poverty Dynamics. Chinese Journal of Population Science (in Chinese), 2011, No. 6: 49-59. 


\section{Appendix}

Table A1 Decomposition of MPI under equal weight with 8 indictors by province and urban

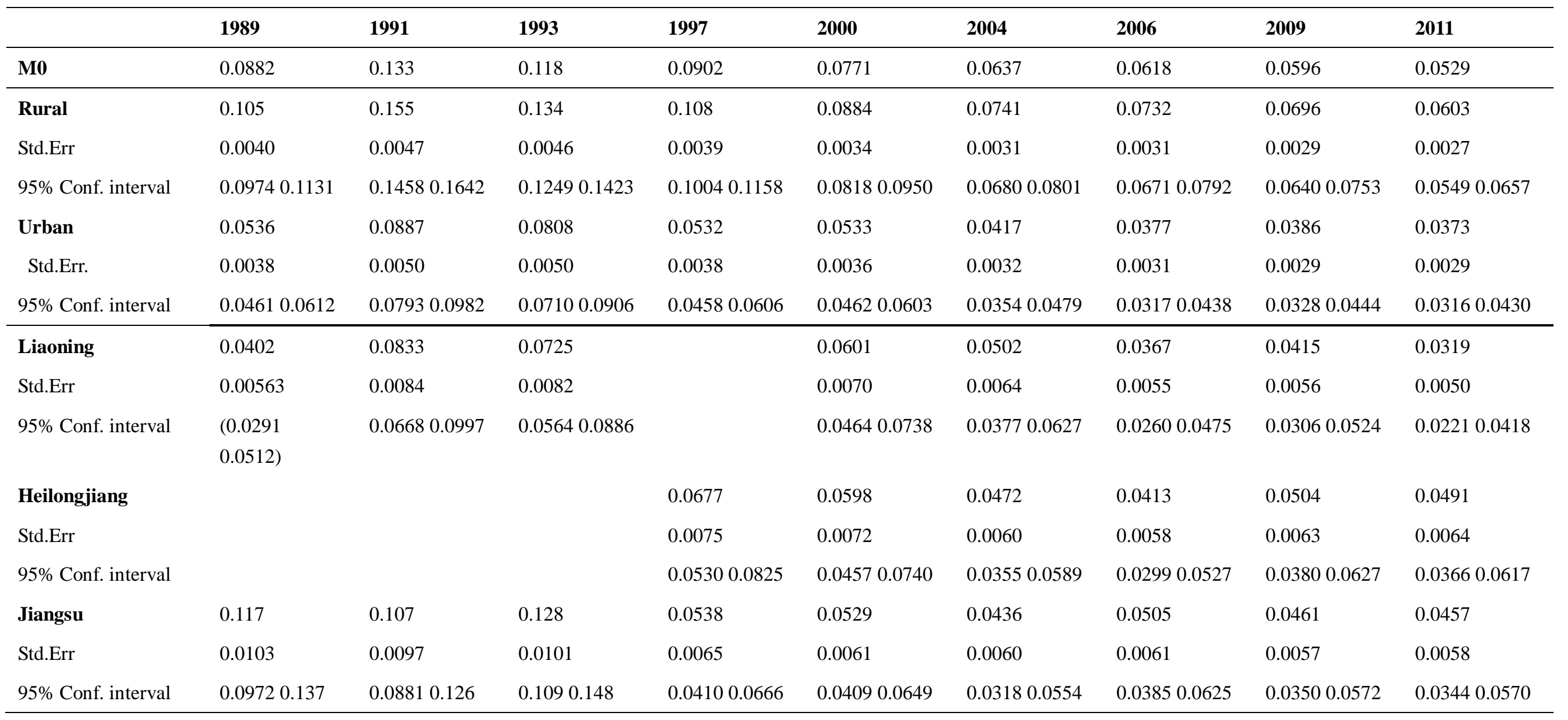




\begin{tabular}{|c|c|c|c|c|c|c|c|c|c|}
\hline Shandong & 0.0400 & 0.0711 & 0.0551 & 0.0396 & 0.0312 & 0.0297 & 0.0273 & 0.0343 & 0.0225 \\
\hline Std.Err & 0.0058 & 0.0077 & 0.0072 & 0.0059 & 0.0053 & 0.0053 & 0.0049 & 0.0053 & 0.0043 \\
\hline $95 \%$ Conf. interval & 0.02860 .0514 & 0.05590 .0863 & 0.04100 .0692 & 0.02790 .0512 & 0.02080 .0416 & 0.01930 .0401 & 0.01770 .0369 & 0.02400 .0446 & 0.01420 .0309 \\
\hline Henan & 0.0992 & 0.110 & 0.0934 & 0.0795 & 0.0522 & 0.0369 & 0.0375 & 0.0358 & 0.0317 \\
\hline Std.Err & 0.0087 & 0.0098 & 0.0095 & 0.0081 & 0.0067 & 0.0054 & 0.0058 & 0.0054 & 0.0050 \\
\hline 95\% Conf. interval & 0.08200 .116 & 0.09110 .129 & 0.07480 .112 & 0.06370 .0954 & 0.04210 .0684 & 0.02640 .0474 & 0.02620 .0488 & 0.02520 .0464 & 0.02180 .0417 \\
\hline Hubei & 0.0882 & 0.159 & 0.126 & 0.113 & 0.100 & 0.0724 & 0.0557 & 0.0477 & 0.0415 \\
\hline Std.Err & 0.0082 & 0.0107 & 0.0101 & 0.0090 & 0.0086 & 0.0076 & 0.0071 & 0.0062 & 0.0056 \\
\hline $95 \%$ Conf. interval & 0.07210 .104 & 0.1380 .180 & 0.1060 .146 & 0.09480 .130 & 0.08350 .117 & 0.05750 .0873 & 0.04160 .0697 & 0.03550 .0600 & 0.03040 .0525 \\
\hline Hunan & 0.0615 & 0.131 & 0.108 & 0.0710 & 0.0672 & 0.0575 & 0.0700 & 0.0632 & 0.0469 \\
\hline Std.Err & 0.0071 & 0.010 & 0.0093 & 0.0074 & 0.0071 & 0.0066 & 0.0069 & 0.0064 & 0.0056 \\
\hline Guangxi & 0.135 & 0.238 & 0.199 & 0.123 & 0.124 & 0.112 & 0.122 & 0.123 & 0.107 \\
\hline Std.Err & 0.0101 & 0.0115 & 0.0112 & 0.0091 & 0.0092 & 0.0086 & 0.0089 & 0.0081 & 0.0079 \\
\hline $95 \%$ Conf. interval & 0.1160 .155 & 0.2160 .261 & 0.1770 .221 & 0.1050 .141 & 0.1060 .142 & 0.09470 .128 & 0.1050 .140 & 0.1070 .138 & 0.09160 .123 \\
\hline Guizhou & 0.126 & 0.159 & 0.146 & 0.167 & 0.137 & 0.119 & 0.109 & 0.0881 & 0.0936 \\
\hline Std.Err & 0.0095 & 0.0103 & 0.0101 & 0.0100 & 0.0096 & 0.0092 & 0.0089 & 0.0078 & 0.0082 \\
\hline $95 \%$ Conf. interval & 0.1070 .144 & 0.1390 .180 & 0.1260 .166 & 0.1470 .187 & 0.1180 .156 & 0.1010 .137 & 0.09190 .127 & 0.07280 .103 & 0.07760 .110 \\
\hline
\end{tabular}


Figure A1 The contribution of each province's MPI to total MPI

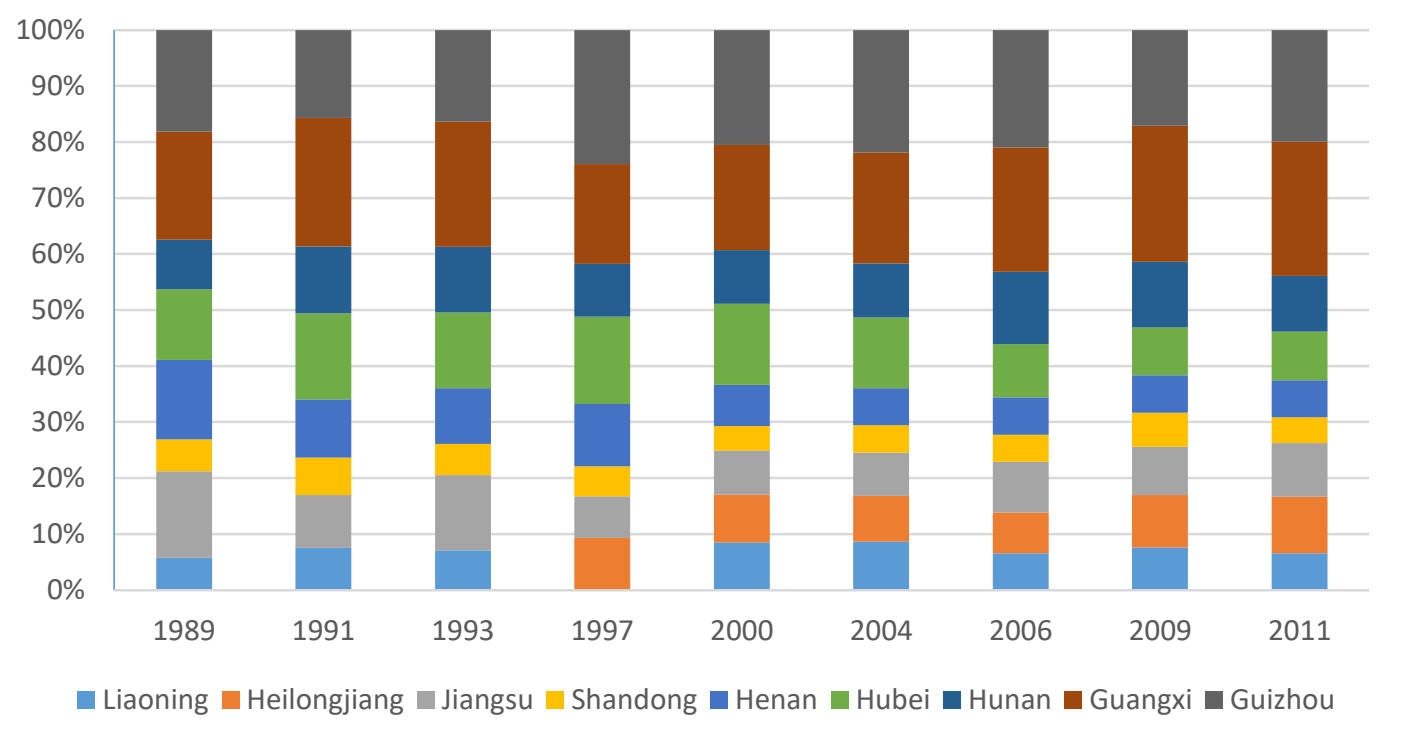

Figure A2 the contribution of rural-urban MPI to total MPI

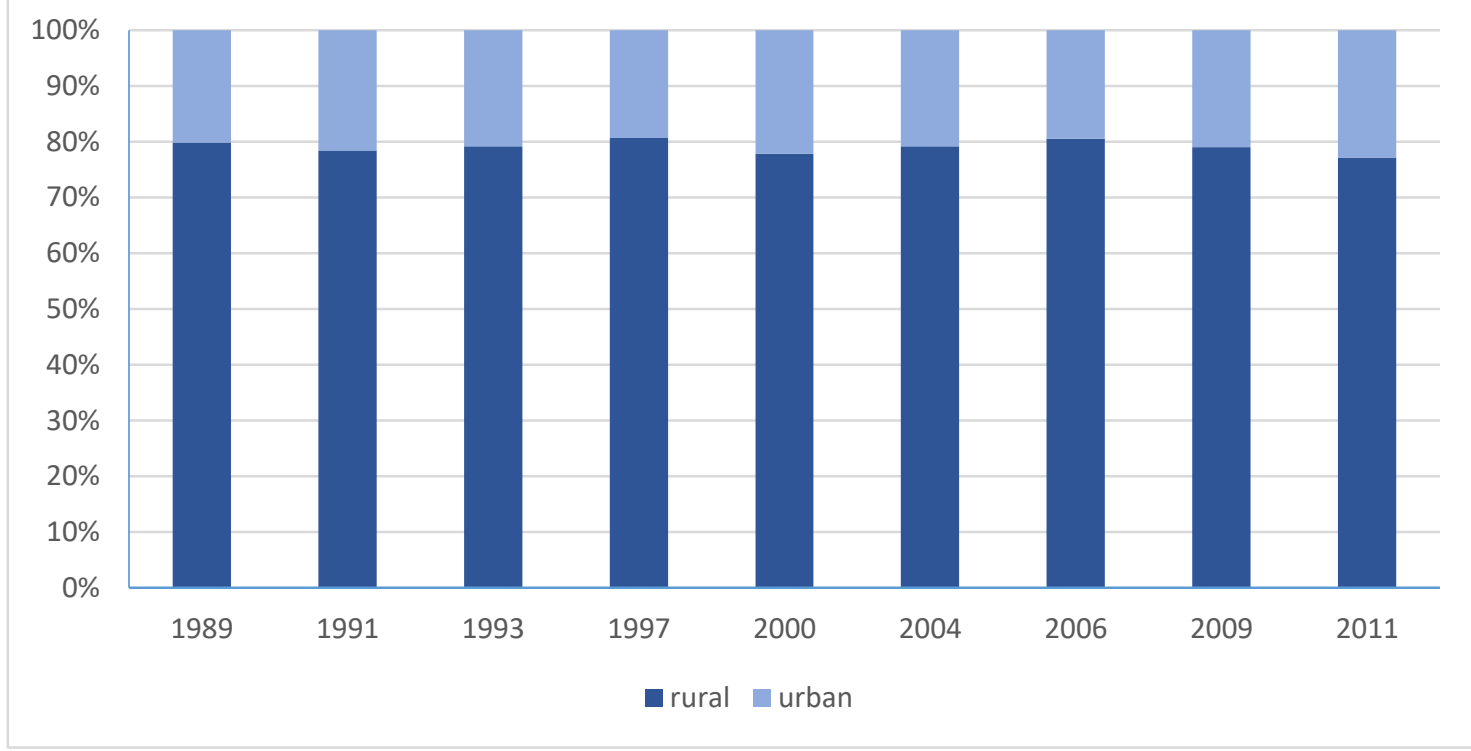


Table A2 Kendall's $\tau$-b rank correlation coefficients for MPI with different weights

\begin{tabular}{|c|c|c|c|c|c|c|c|}
\hline & & Weight0 & Weight1 & Weight2 & Weight3 & Weight4 & Weight5 \\
\hline \multirow[t]{6}{*}{1989} & Weight0 & 0.9970 & & & & & \\
\hline & Weight1 & $0.6804 *$ & 1.0000 & & & & \\
\hline & Weight2 & $0.8046^{*}$ & $0.6734^{*}$ & 1.0000 & & & \\
\hline & Weight3 & $0.4139 *$ & $0.8216^{*}$ & $0.4874 *$ & 1.0000 & & \\
\hline & Weight4 & $0.6828 *$ & $0.7885^{*}$ & $0.6547 *$ & $0.5890 *$ & 1.0000 & \\
\hline & Weight5 & $0.7662 *$ & $0.6186^{*}$ & $0.6611 *$ & $0.3304 *$ & $0.7324 *$ & 1.0000 \\
\hline \multirow[t]{6}{*}{1991} & Weight0 & 0.9960 & & & & & \\
\hline & Weight1 & $0.6395^{*}$ & 1.0000 & & & & \\
\hline & Weight2 & $0.8053 *$ & $0.6935^{*}$ & 1.0000 & & & \\
\hline & Weight3 & $0.5101 *$ & $0.9264 *$ & $0.6158 *$ & 1.0000 & & \\
\hline & Weight4 & $0.6976^{*}$ & $0.8445^{*}$ & $0.7310^{*}$ & $0.7564 *$ & 1.0000 & \\
\hline & Weight5 & $0.6592 *$ & $0.4398 *$ & $0.5496^{*}$ & $0.2573^{*}$ & $0.5465^{*}$ & 1.0000 \\
\hline \multirow[t]{6}{*}{1993} & Weight0 & 0.9960 & & & & & \\
\hline & Weight1 & $0.5729 *$ & 1.0000 & & & & \\
\hline & Weight2 & $0.7253 *$ & $0.6788 *$ & 1.0000 & & & \\
\hline & Weight3 & $0.4074 *$ & $0.9257^{*}$ & $0.5717 *$ & 1.0000 & & \\
\hline & Weight4 & $0.6209 *$ & $0.8721 *$ & $0.7289 *$ & $0.7841 *$ & 1.0000 & \\
\hline & Weight5 & $0.7659 *$ & $0.4286^{*}$ & $0.5723 *$ & $0.2200 *$ & $0.5045^{*}$ & 1.0000 \\
\hline \multirow[t]{6}{*}{1997} & Weight0 & 0.9970 & & & & & \\
\hline & Weight1 & $0.5329 *$ & 1.0000 & & & & \\
\hline & Weight2 & $0.6847 *$ & $0.6415^{*}$ & 1.0000 & & & \\
\hline & Weight3 & $0.3957 *$ & $0.9442 *$ & $0.5566 *$ & 1.0000 & & \\
\hline & Weight4 & $0.5950^{*}$ & $0.8551 *$ & $0.7171 *$ & $0.7828 *$ & 1.0000 & \\
\hline & Weight5 & $0.5532 *$ & $0.3082 *$ & $0.4272 *$ & $0.1868 *$ & $0.3691 *$ & 1.0000 \\
\hline \multirow[t]{6}{*}{2000} & Weight0 & 0.9970 & & & & & \\
\hline & Weight1 & $0.5034 *$ & 1.0000 & & & & \\
\hline & Weight2 & $0.6756 *$ & $0.6077 *$ & 1.0000 & & & \\
\hline & Weight3 & $0.3423 *$ & $0.9421 *$ & $0.5098 *$ & 1.0000 & & \\
\hline & Weight4 & $0.5814 *$ & $0.8375^{*}$ & $0.7028 *$ & $0.7579 *$ & 1.0000 & \\
\hline & Weight5 & $0.7445^{*}$ & $0.3749 *$ & $0.5356^{*}$ & $0.1748 *$ & $0.4706^{*}$ & 1.0000 \\
\hline \multirow[t]{2}{*}{2004} & Weight0 & 0.9980 & & & & & \\
\hline & Weight1 & $0.4897 *$ & 1.0000 & & & & \\
\hline
\end{tabular}




\begin{tabular}{|c|c|c|c|c|c|c|c|}
\hline & Weight2 & $0.6213 *$ & $0.5405^{*}$ & 1.0000 & & & \\
\hline & Weight3 & $0.3458 *$ & $0.9531 *$ & $0.4558 *$ & 1.0000 & & \\
\hline & Weight4 & $0.5765^{*}$ & $0.8200 *$ & $0.6509 *$ & $0.7513 *$ & 1.0000 & \\
\hline & Weight5 & $0.4410^{*}$ & $0.2361 *$ & $0.2931 *$ & $0.1892 *$ & $0.2826^{*}$ & 1.0000 \\
\hline \multirow[t]{6}{*}{2006} & Weight0 & 0.9980 & & & & & \\
\hline & Weight1 & $0.5473^{*}$ & 1.0000 & & & & \\
\hline & Weight2 & $0.6745^{*}$ & $0.5166^{*}$ & 1.0000 & & & \\
\hline & Weight3 & $0.3797 *$ & $0.9381 *$ & $0.4107^{*}$ & 1.0000 & & \\
\hline & Weight4 & $0.6640 *$ & $0.8117^{*}$ & $0.6405^{*}$ & $0.7179 *$ & 1.0000 & \\
\hline & Weight5 & $0.6025^{*}$ & $0.3296 *$ & $0.4278 *$ & $0.1954 *$ & $0.4142 *$ & 1.0000 \\
\hline \multirow[t]{6}{*}{2009} & Weight0 & 0.9980 & & & & & \\
\hline & Weight1 & $0.4340 *$ & 1.0000 & & & & \\
\hline & Weight2 & $0.6260 *$ & $0.3919 *$ & 1.0000 & & & \\
\hline & Weight3 & $0.2821 *$ & $0.9577 *$ & $0.3004^{*}$ & 1.0000 & & \\
\hline & Weight4 & $0.5796 *$ & $0.7477^{*}$ & $0.5458^{*}$ & $0.6740^{*}$ & 1.0000 & \\
\hline & Weight5 & $0.6003 *$ & $0.2440 *$ & $0.4284^{*}$ & $0.0768 *$ & $0.3626^{*}$ & 1.0000 \\
\hline \multirow[t]{6}{*}{2011} & Weight0 & 0.9980 & & & & & \\
\hline & Weight1 & $0.4559 *$ & 1.0000 & & & & \\
\hline & Weight2 & $0.6525^{*}$ & $0.4021 *$ & 1.0000 & & & \\
\hline & Weight3 & $0.3020 *$ & $0.9553^{*}$ & $0.3051 *$ & 1.0000 & & \\
\hline & Weight4 & $0.6140 *$ & $0.7288 *$ & $0.5638 *$ & $0.6500^{*}$ & 1.0000 & \\
\hline & Weight5 & $0.6856^{*}$ & $0.3065 *$ & $0.5008 *$ & $0.1443 *$ & $0.4553^{*}$ & 1.0000 \\
\hline
\end{tabular}

Note:(1) * stands for statistically significant of the correlation coefficients at the 5\% level or lower. (2) weight0 refers to MPI under equal weight for each dimension with 10 indicators; weight1 refers to MPI under equal weight for each dimension with 8 indicators; weight 2 refers to MPI with the weight structure $50 \% 25 \% 25 \%$ for education, health and living standard; weight 3 refers to MPI with the weight structure $25 \% 50 \% 25 \%$ for three dimensions; weight4 refers to MPI with the weight structure $25 \% 25 \% 50 \%$ for three dimensions and weight5 refers to MPI under the frequency weight. 
Figure A3 The dominance analysis on MD poverty with the self-reported health indicators

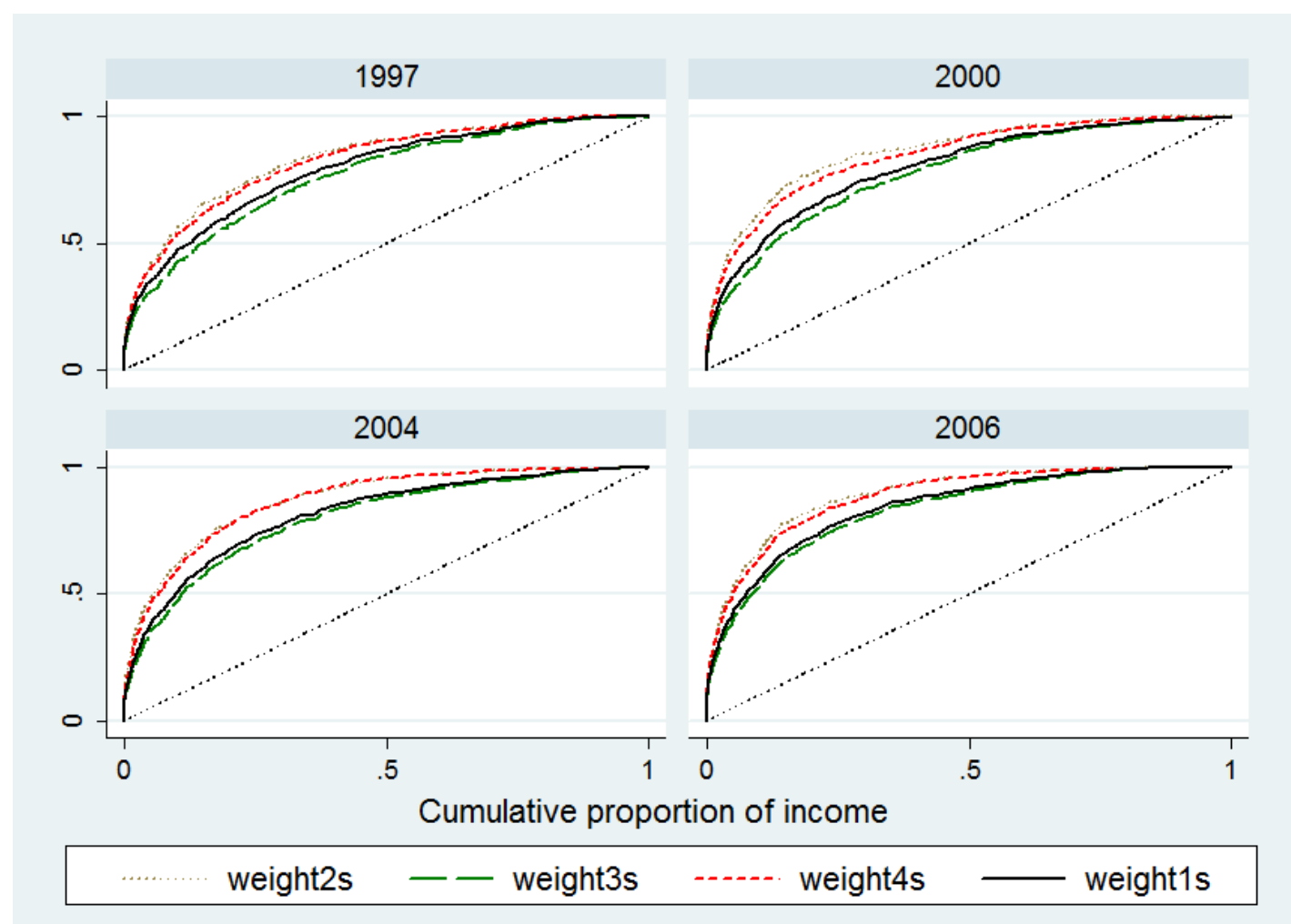

Note: weight1s to weight4s refers to Multidimensional poverty under weight1 to weight4 with self-reported health indicators. weight $1 \mathrm{~s}$, weight $2 \mathrm{~s}$, weight $3 \mathrm{~s}$ and weight $4 \mathrm{~s}$ refer to equal weights, $50 \%$ $25 \% 25 \%, 25 \% 50 \% 25 \%, 25 \% 25 \% 50 \%$ for education, health and standard of living, respectively. 
Figure A4 The dominance analysis on MD poverty under different health indicators
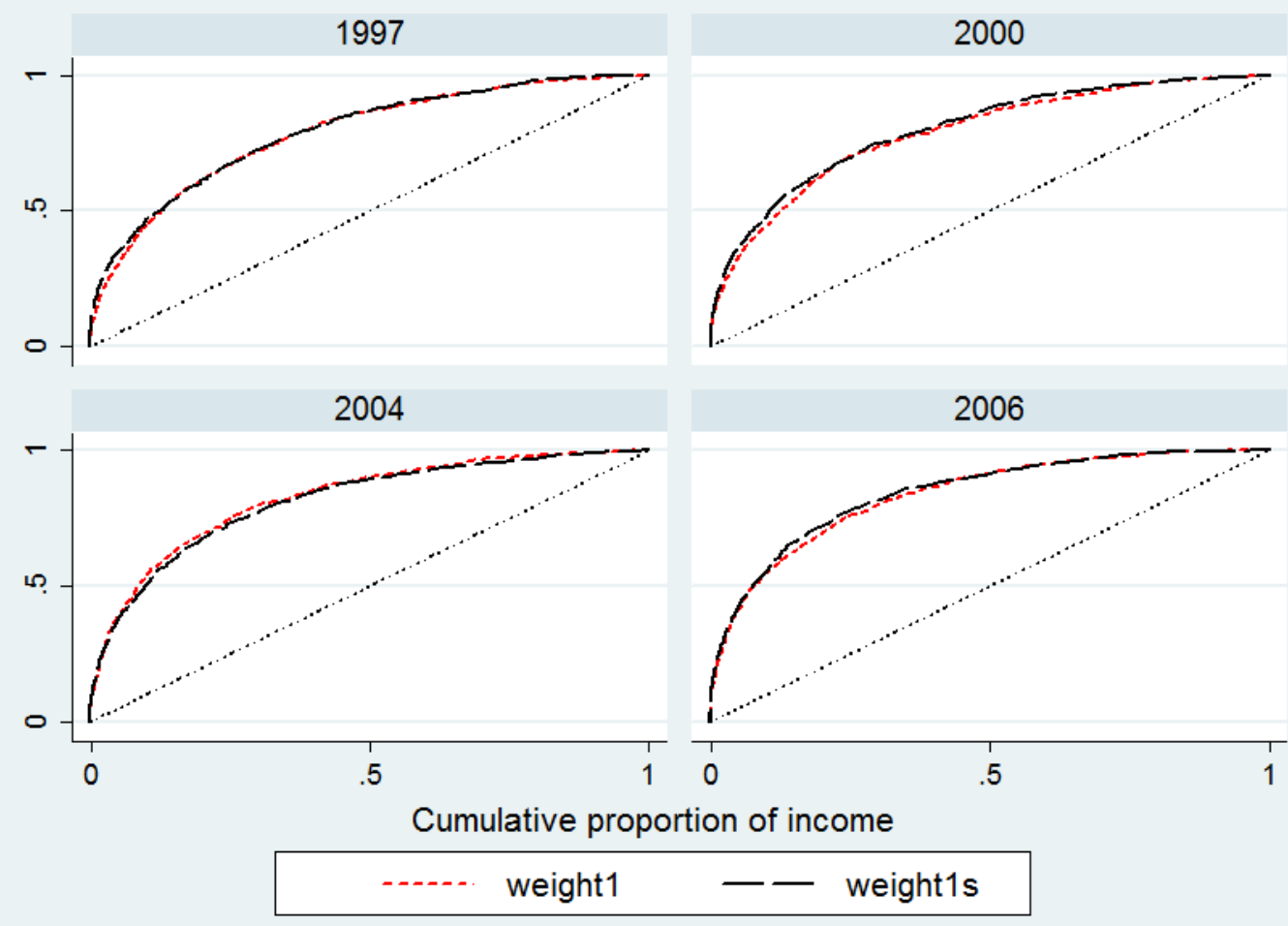

Figure A5 The dominance analysis on MD poverty under different health indicators
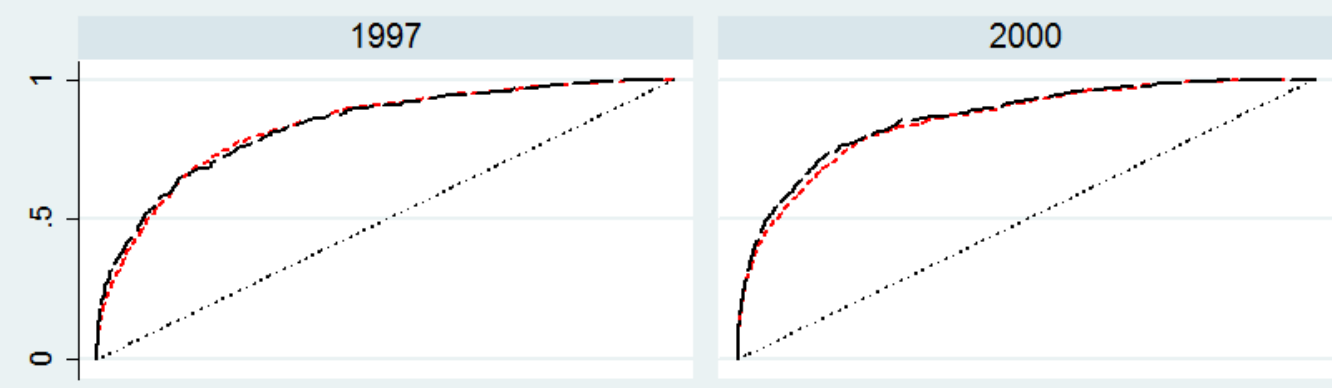

2004

2006

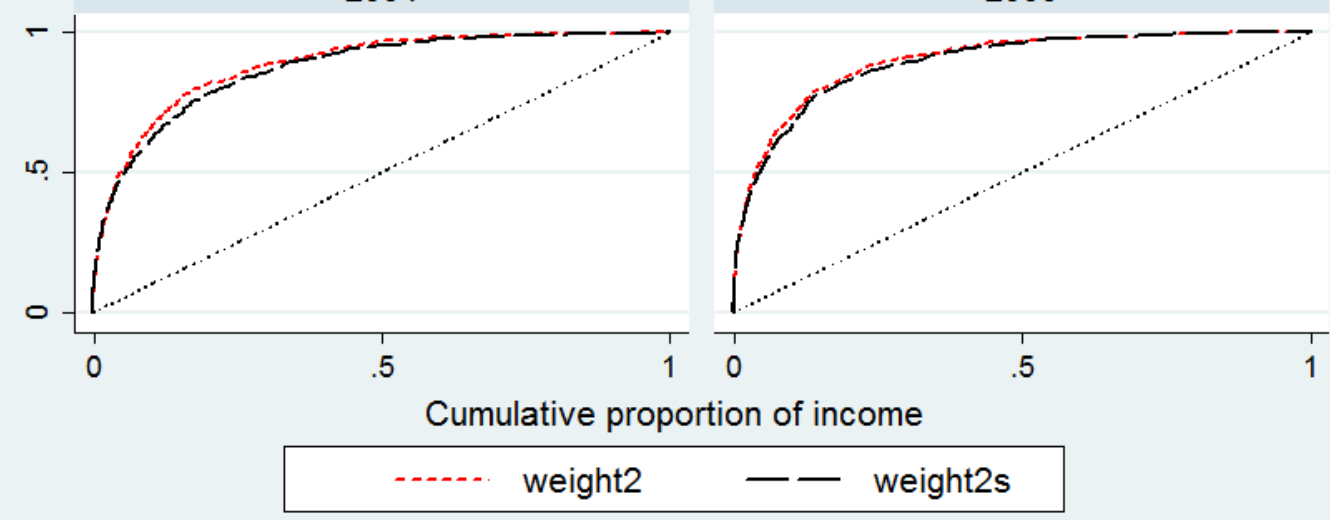


Figure A6 The dominance analysis on MD poverty under different health indicators
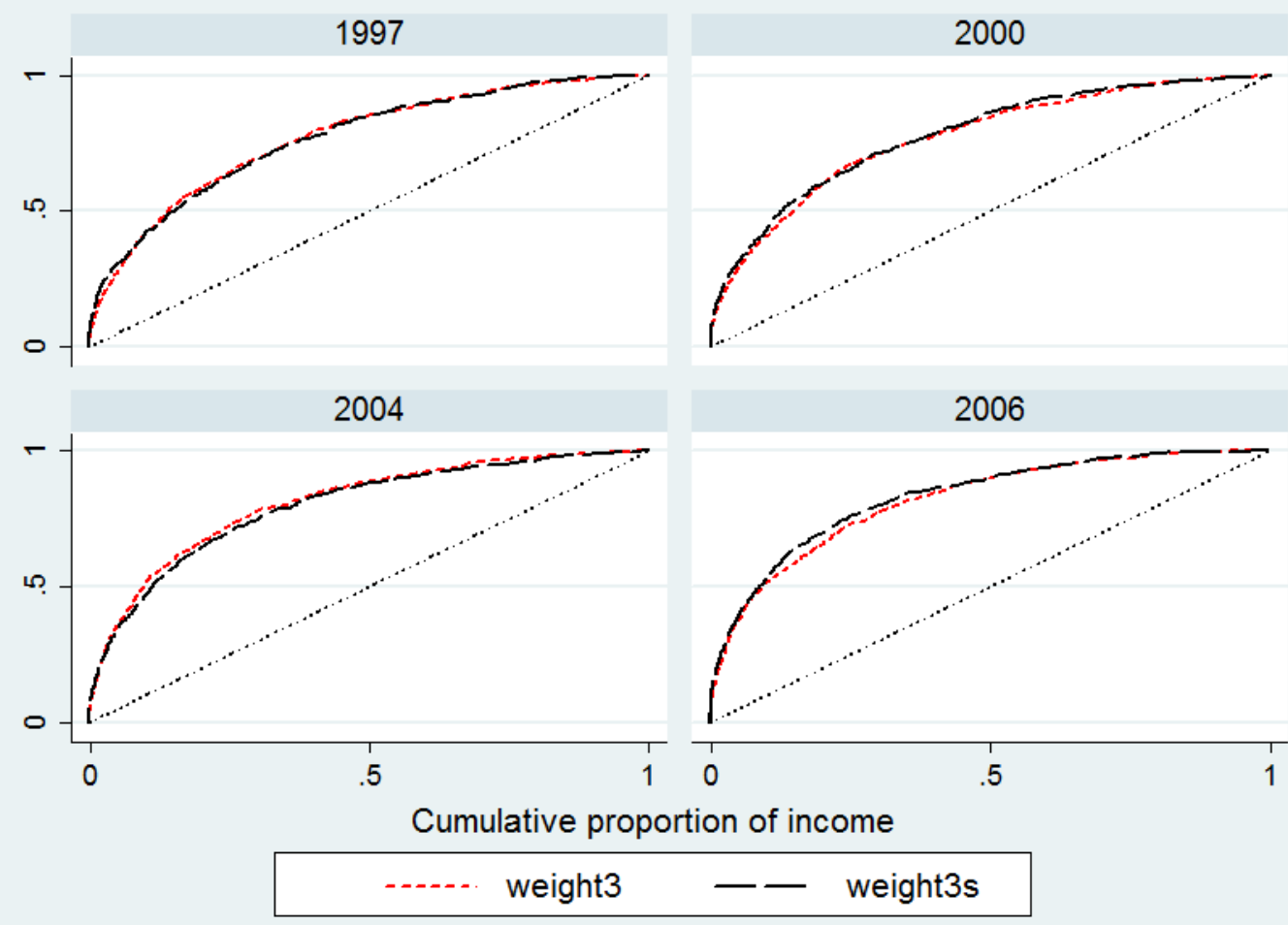

Figure A7 The dominance analysis on MD poverty under different health indicators
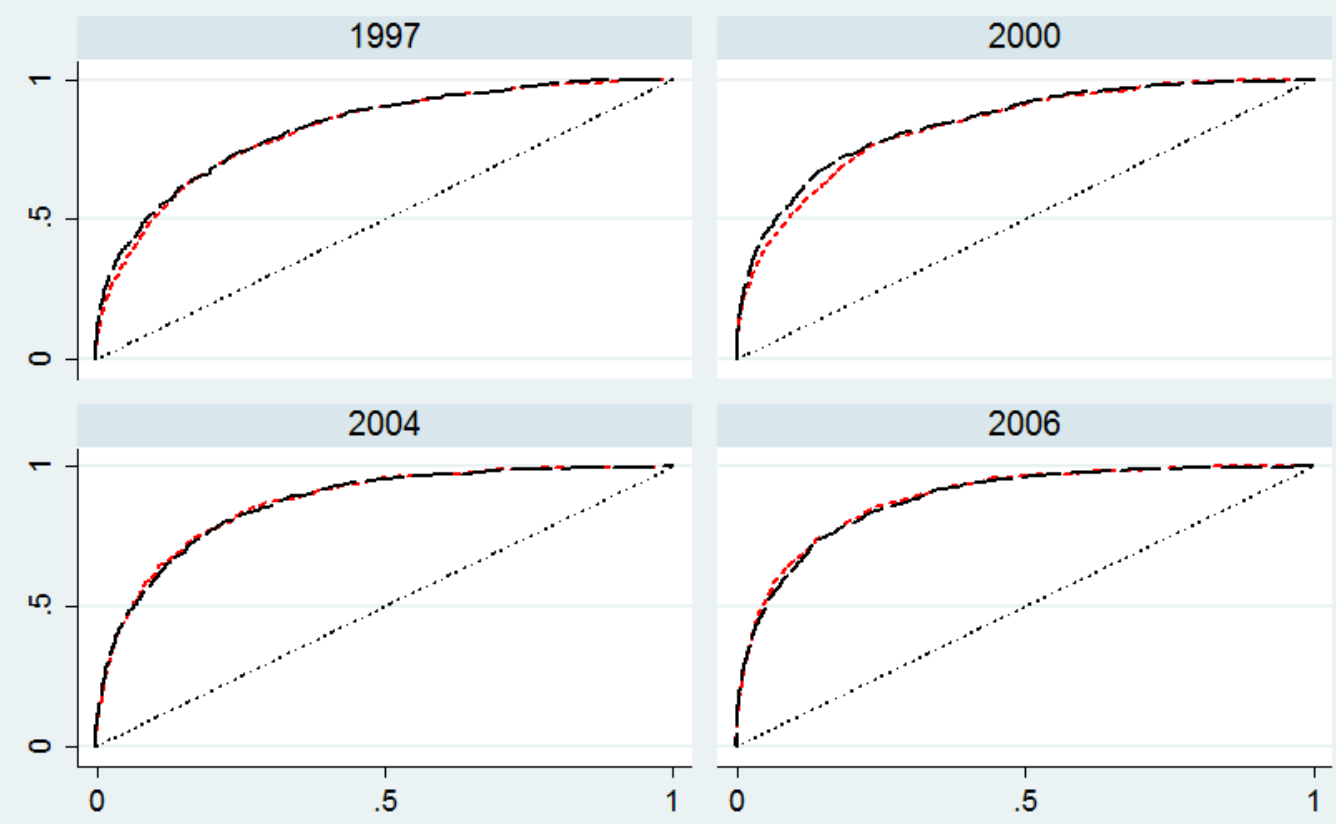

Cumulative proportion of income

$$
\text { -.-.- weight4 - weight4s }
$$


Figure A8 The dominance analysis of different multidimensional measures
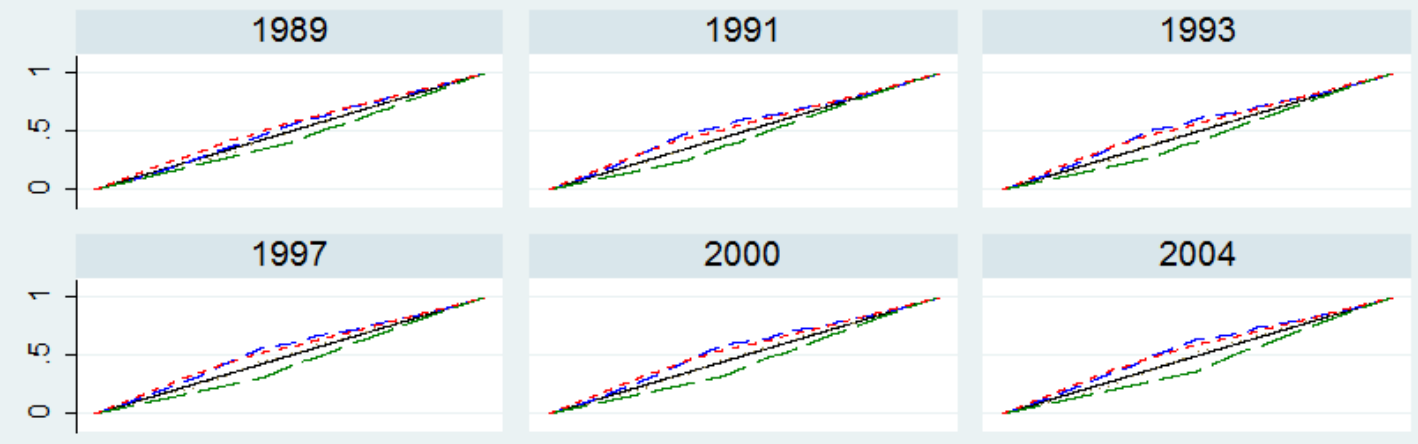

2006

2009

2011
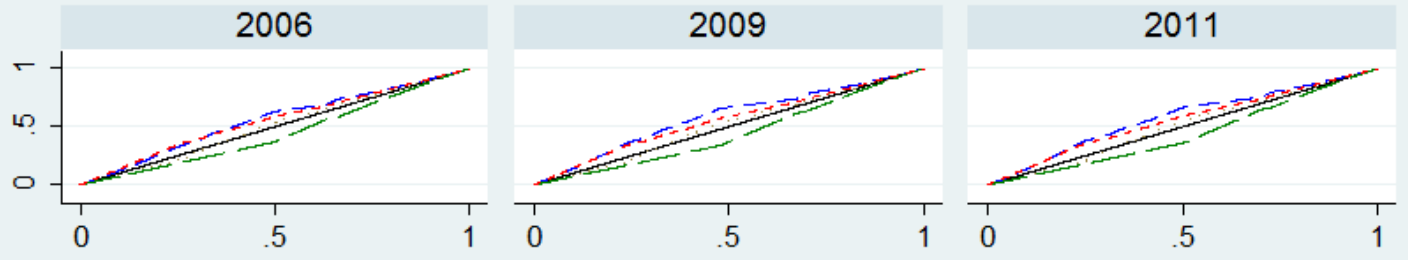

The cumulative proportion of mdp under weight $1(1 / 3,1 / 3,1 / 3)$

\begin{tabular}{|c|c|}
\hline - Diagnoal line & ---- frequency weight \\
\hline weight2(1/2,1/4,1/4) & - weight $3(1 / 4,1 / 2,1 / 4)$ \\
\hline
\end{tabular}

Graphs by SURVEY YEAR 